\title{
A Numerical Sensitivity Analysis of Soil Moisture Feedback on Convective Precipitation
}

\author{
MARIKA KOUKOULA \\ Department of Civil and Environmental Engineering, University of Connecticut, Storrs, Connecticut, and \\ Atmospheric Modeling and Weather Forecasting Group, Department of Physics, \\ National and Kapodistrian University of Athens, Athens, Greece \\ EFTHYMIOS I. NiKOLOPOULOS \\ Department of Civil and Environmental Engineering, University of Connecticut, Storrs, Connecticut \\ JONILDA KUSHTA \\ Energy, Environment and Water Research Centre, The Cyprus Institute, Nicosia, Cyprus \\ NikolaOs S. BARTSOTAS ANd GeORge Kallos \\ Atmospheric Modeling and Weather Forecasting Group, Department of Physics, \\ National and Kapodistrian University of Athens, Athens, Greece \\ EMMANOUIL N. ANAGNOSTOU \\ Department of Civil and Environmental Engineering, University of Connecticut, Storrs, Connecticut
}

(Manuscript received 26 June 2018, in final form 14 October 2018)

\begin{abstract}
Of the boundary conditions that affect the simulation of convective precipitation, soil moisture is one of the most important. In this study, we explore the impact of the soil moisture on convective precipitation, and factors affecting it, through an extensive numerical experiment based on four convective precipitation events that caused moderate to severe flooding in the Gard region of southern France. High-spatial-resolution (1 km) weather simulations were performed using the integrated atmospheric model Regional Atmospheric Modeling System/Integrated Community Limited Area Modeling System (RAMS/ICLAMS). The experimental framework included comparative analysis of five simulation scenarios for each event, in which we varied the magnitude and spatial distribution of the initial volumetric water content using realistic soil moisture fields with different spatial resolution. We used precipitation and surface soil moisture from radar and satellite sensors as references for the comparison of the sensitivity tests. Our results elucidate the complexity of the relationship between soil moisture and convective precipitation, showing that the control of soil water content on partitioning land surface heat fluxes has significant impacts on convective precipitation. Additionally, it is shown how different soil moisture conditions affect the modeled microphysical structure of the clouds, which translates into further changes in the magnitude and distribution of precipitation.
\end{abstract}

\section{Introduction}

Despite advances in numerical weather prediction (NWP) models over the past few decades, the simulation of convective precipitation remains a challenge. The chaotic nature of atmospheric processes (Fritsch et al. 1998),

\footnotetext{
Corresponding author: Emmanouil Anagnostou, manos@uconn. edu
}

the uncertainty of initial and boundary conditions, and the incomplete description of physical processes can influence the performance of NWP models with regard to quantitative precipitation forecasting. Among the most important boundary conditions affecting the overlying atmosphere is soil moisture. As pointed out by Dirmeyer et al. (1999), soil moisture determines the partitioning of land surface heat flux between the sensible and latent components, thus affecting both heat 
and water balances. Additionally, mesoscale circulation forced by soil moisture patterns can trigger convection (Trier et al. 2004).

Numerous observational and modeling studies have explored the interaction of soil moisture and convection across a wide range of spatial and temporal scales (Segal et al. 1989; Pielke et al. 1989). By varying the initial volumetric soil moisture content from $60 \%$ drier to $30 \%$ wetter than a control simulation, Gallus and Segal (2000) found an increase in surface precipitation in the midwestern United States. Cheng and Cotton (2004), on the other hand, tested the sensitivity of varying soil moisture initialization on a mesoscale convective system (MCS) simulation in Texas and found wetter soil had a tendency to suppress convection. Simulations by Van Weverberg et al. (2010) of two extreme convection events with different soil moisture initializations and microphysical parameterization schemes demonstrated an inverse relationship between surface precipitation and soil moisture content. Hohenegger et al. (2009) conducted simulations with resolved and parameterized convection to investigate feedback between soil moisture and precipitation over the European Alps, for a period of one month. According to their findings, the two different systems yielded different convection strengths and signs of feedbacks, with the high-resolution simulation finding a negative soil moisture-precipitation feedback.

Soil moisture remains one of the largest sources of uncertainty in initial and boundary conditions of atmospheric simulations. The increasing availability of global soil moisture datasets has made possible some recent studies in this area. Panegrossi et al. (2011) used a highresolution soil moisture field dataset derived from Envisat Advanced Synthetic Aperture Radar (ASAR) observations to generate soil moisture initial conditions for a simulation of the Tanaro flood event of April 2009. The use of drier, high-resolution soil moisture content showed a significant impact on the accuracy of the precipitation forecast, mainly during the early phase of the event. Hauck et al. (2011) used soil moisture monitoring data to analyze the discrepancies between observed and modeled soil moisture fields and their potential impacts on the convective precipitation forecast. They concluded that whereas a systematic relationship with soil moisture exists for a number of convection-related parameters, the response of convective precipitation to initial soil moisture is more complex. Investigating possible relationships between soil moisture and precipitation, Khodayar and Schädler (2013) performed numerical experiments using soil moisture observations. They found realistic initiation of the model with soil moisture observations could affect the simulations until an extreme precipitation event removed the initial soil moisture dependency. They also noted a local positive feedback between the soil moisture and precipitation. Spatial variability of soil moisture constitutes a very important aspect of the initiation and development of convection. Adler et al. (2011) investigated the impact of soil moisture spatial variability on a MCS using idealized soil moisture fields. They found that the soil moisture patterns altered the convectionrelated parameters and thus modified the MCS. Ronda et al. (2002) concluded that a proper representation of the season hydrological cycle in large-scale atmospheric models requires taking account of the spatial heterogeneity of the soil moisture content.

Tuttle and Salvucci (2016), in a more recent study, stated that soil moisture anomalies significantly influence rainfall in the United States. Specifically, they found a positive relationship between soil moisture and precipitation in the western United States and a negative feedback in the east, concluding that the relationship depends on the regional aridity. Guillod et al. (2014) used satellite-derived precipitation and soil moisture data to investigate the relationship between soil moisture and afternoon rainfall. They found a positive temporal and negative spatial coupling between soil moisture and precipitation. They stated that wetter soil might enhance precipitation persistence while precipitation occurs more often over dry soils. Wang et al. (2018) used the convergent cross-mapping method to investigate the soil moisture-precipitation relationship. They concluded that the effect of soil moisture on precipitation is evident with a lag of one month.

In summary, all these past studies have demonstrated that a relationship between soil moisture and precipitation is evident and the magnitude and sign of impact depends strongly on the characteristics of the region, the atmospheric conditions, and the model physical and parametric configuration. However, no unidirectional feedback (i.e., only positive or only negative) between soil moisture and convective precipitation has emerged from these various investigations. The reasons for the contradictory findings pertain to both physical aspects but can also be attributed to technical specifications. The former highlights the complexity in physical mechanisms involved in soil moisture-precipitation relationship, while the latter refers to the impact of different experimental designs in numerical-based investigations and relates also to uncertainty induced by differences in model structure, model resolution, etc. As an example, a large body of studies has focused on idealized experiments that, although they offer insight on the mechanisms involved, refer to conditions that may not be realistic. Therefore, to further advance our understanding of soil moisture 


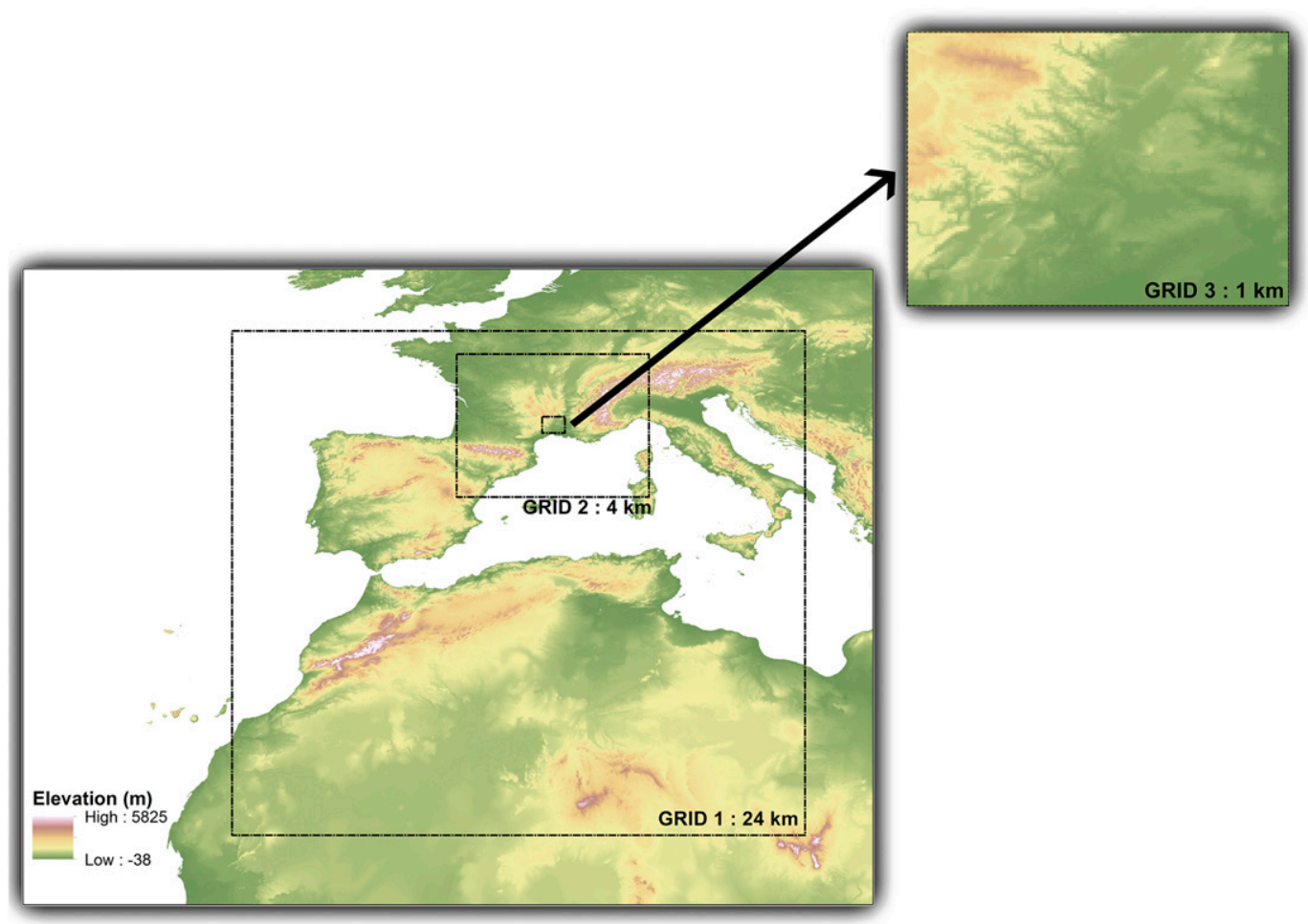

FIG. 1. Extent of the model domains for the RAMS/ICLAMS simulations. The area of analysis of the current study is represented in GRID 3.

impact on convective precipitation, it is important to focus on the examination of realistic soil moisture characteristics (magnitude and spatial variability) and apply a consistent experimental framework for various atmospheric conditions.

This work relies on the current availability of global soil moisture estimates from satellite and land surface models to derive realistic representation of soil moisture fields and applies a consistent sensitivity analysis framework to further investigate the complex relationship between soil moisture and convective precipitation and its dependence on meteorological conditions and initial soil moisture characteristics (magnitude and variability). Using four different case studies corresponding to floodinducing convective rainfall events that occurred over the Gard region of southern France, we conducted a number of sensitivity simulations (five per event) to 1) estimate the impact of soil moisture on convective precipitation under different meteorological conditions and 2) gain further insight into the relationships and feedbacks between soil moisture and convective-related parameters.

This paper is organized into seven sections. The next section (section 2) presents the main climatological and soil characteristics of the study area. Section 3 describes the meteorological characteristics of the four convective rainfall events, while section 4 introduces a short description of the atmospheric model we used for the simulations and the model configuration, as well as the soil moisture and precipitation datasets used in the current work. Section 5 presents the experimental setup (i.e., the methodology we adopted). The main results of the analysis of the sensitivity tests appear in section 6 , and section 7 discusses our main findings and presents our conclusions.

\section{Study area}

The region under consideration is the wider area of Gard in the south of France (Fig. 1). We selected this area because of the high frequency of heavy precipitation events triggered by local atmospheric circulation (Delrieu et al. 2005; Anquetin et al. 2003) and the availability of high-quality precipitation observations from weather radar (Delrieu et al. 2014; Boudevillain et al. 2016).

The Gard region has a typical Mediterranean climate. Molinié et al. (2012) note that the seasonal cycle of monthly rainfall amounts exhibits two maxima; the higher one occurs during the fall season and the lower one during the spring. The nearby Mediterranean Sea acts as an energy and moisture source for the lower layers of the atmosphere, leading to frequent flood-inducing 
storm events in the region. Moreover, the complex terrain of the wider area surrounded by the Alps, Pyrenees, and Massif Central Mountains contributes to convection triggering and channels the low-level flows, enhancing convective instability. The average depth in the region does not exceed $55 \mathrm{~cm}$ (Anquetin et al. 2009), and the average texture over the whole region consists of around $50 \%$ sand, $30 \%$ silt, and $20 \%$ clay (Manus et al. 2009).

\section{Case studies}

The Gard region is the part of France most frequently affected by flash floods (Gaume et al. 2009). For this study, we selected four convective rainfall events that caused heavy precipitation and flooding in the area. A description of the meteorological conditions associated with each event is given.

\section{a. 8-9 September 2002}

A heavy precipitation event that took place 8-9 September 2002 was responsible for one of the most severe floods ever recorded in the Gard region, resulting in 24 deaths and an estimated $\$ 1$ billion (U.S. dollars) in economic damage (Huet et al. 2003). This catastrophic precipitation event was caused by a quasi-stationary MCS associated with an upper-level cold low centered over Ireland and extending to the Iberian Peninsula, which generated a southwesterly flow over the area on 8 September. The quasi-stationary MCS stayed over the Gard region until the next day, when a cold frontal system passed over and contributed to heavy precipitation (Delrieu et al. 2005). The 24-h accumulated precipitation reached $700 \mathrm{~mm}$, with $500 \mathrm{~mm}$ recorded in less than $9 \mathrm{~h}$ (Anquetin et al. 2005).

\section{b. 31 October-2 November 2008}

The second event was a convective storm episode, with observed rainfall amounts of up to $365 \mathrm{~mm}$ in $24 \mathrm{~h}$ (Fresnay et al. 2012). The event started on 31 October 2008, when an occluded front system passed over the region, resulting in rainfall rates of up to $16 \mathrm{~mm} \mathrm{~h}^{-1}$. The next day, 1 November, a large trough over western France caused a very strong, low-level jet, bringing moist, unstable air that was lifted by the Massif Central. The presence of an upper-level low at the west of the region induced a strong divergent flow over southeastern France, resulting in deep convection. Accumulated precipitation amounts up to $744 \mathrm{~mm}$ in $49 \mathrm{~h}$ were recorded, and rainfall rates reached almost $80 \mathrm{~mm} \mathrm{~h}^{-1}$.

\section{c. 6-8 September 2010}

A third heavy precipitation event began on 6 September 2010 , when a low pressure system over the Iberian
Peninsula moved toward the Gard region, generating a southwesterly flow and ascending motions. On September 7 , the area was both under the diffluent part of an upperlevel trough over Spain and the left-exit region of a moderate upper-level jet streak, causing deep convection. These systems affected the area for $32 \mathrm{~h}$, bringing high amounts of convective rainfall. The 42-h accumulated precipitation reached almost $400 \mathrm{~mm}$, while rainfall rates exceeding $130 \mathrm{~mm} \mathrm{~h}^{-1}$ were recorded.

\section{d. 19-21 May 2012}

The last event analyzed in the current study was a mild rainfall episode that started on 19 May 2012 and lasted $30 \mathrm{~h}$. An easterly-moving low-level system west of the Gard region, along with an upper-level low over the Iberian Peninsula moving southeasterly, generated a southwesterly flow that brought moist air from the Mediterranean Sea. On 20 May, a cold frontal system passed over the area, bringing significant rainfall. Records show a 48-h accumulated precipitation amount of up to $122 \mathrm{~mm}$, while the rainfall rate reached almost $44 \mathrm{~mm} \mathrm{~h}^{-1}$.

\section{Model configuration and datasets}

\section{a. Description and setup of the model}

For the simulation of the four rainfall events described above, we used the integrated atmospheric model Regional Atmospheric Modeling System/Integrated Community Limited Area Modeling System (RAMS/ICLAMS; Solomos et al. 2011; Kushta et al. 2014). The Atmospheric Modeling and Weather Forecasting Group at the University of Athens developed ICLAMS based on RAMS version 6 (Pielke et al. 1992; Cotton et al. 2003). The detailed two-moment (mass and number) bulk microphysical scheme (Meyers et al. 1997) describing the in-cloud processes for seven categories of hydrometeors (cloud droplets, rain droplets, pristine ice, snow, aggregates, graupel, and hail) included in this model makes it suitable for high-resolution simulation of clouds and precipitation.

For this study, we used a three-grid setup with a coarse external domain of $24-\mathrm{km}$ resolution (total size of $3360 \mathrm{~km} \times$ $3360 \mathrm{~km}$ ) and two nested domains with $4 \mathrm{~km}$ (total size of $896 \mathrm{~km} \times 896 \mathrm{~km}$ ) and $1 \mathrm{~km}$ (total size of $166 \mathrm{~km} \times$ $182 \mathrm{~km}$ ) horizontal grid spacing, respectively (Fig. 1). Two-way nesting was activated for both inner domains. Vertically, the domain stretches up to $13.3 \mathrm{~km}$ with 32 layers, with the top of the first layer located $24 \mathrm{~m}$ above ground. Convective activity on the outer domain (resolution of $24 \mathrm{~km}$ ) is parameterized using the KainFritsch scheme (Kain and Fritsch 1993; Kain 2004). 
The topography (USGS 2018a) and vegetation (USGS 2018b) data are derived from the U.S. Geological Survey (USGS) $30^{\prime \prime} \times 30^{\prime \prime}$ dataset and the soil texture from Zobler and FAO/UNESCO (Webb et al. 2000) at $2^{\prime} \times 2^{\prime}$ resolution. We used the Final (FNL) Operational Global Analysis data of the National Centers for Environmental Prediction (NCEP), with $1^{\circ} \times 1^{\circ}$ spatial resolution as initial and lateral conditions, and the NCEP $0.5^{\circ} \times 0.5^{\circ}$ sea surface temperature (SST) analysis for water body initial conditions. The boundary conditions of the nested domains are provided by the respective parent grid. The land surface model in RAMS/ICLAMS is the Land Ecosystem Atmospheric Feedback model, version 3 (LEAF-3; Walko and Tremback 2005). Its default initial soil moisture field is based on a vertically varying profile of soil water content, and the characteristics (saturation volumetric moisture content, sand fraction) of each of the 12 U.S. Department of Agriculture (USDA) soil texture classifications used in the land surface model. Based on the characteristics of the region under study and/or climatological values, the user can define different initial soil moisture values for each layer below the surface, but the soil moisture values are spatially homogeneous across the model domain. For this study we used eight soil layers down to $1 \mathrm{~m}$ below surface (the bottom of each soil layer is $0.05,0.1,0.2,0.3,0.4,0.6,0.8$, and $1 \mathrm{~m}$ below ground, respectively).

\section{b. Datasets}

For the initial conditions of the simulations performed in this study, we used simulated soil moisture datasets, and for the evaluation of the model performance, we used remote sensing estimates of soil moisture and rainfall. In this section we present a brief description of these datasets.

We used two datasets for initial soil moisture conditions. The first was the Earth2Observe tier-1 water resources reanalysis (WRR1) dataset. The WRR1 dataset (Schellekens et al. 2017) consists of an ensemble of 10 global hydrological and land surface model simulations for the period 1979-2012, driven by a reanalysisbased meteorological forcing dataset. In this study we used the surface $(5 \mathrm{~cm}$ ) and root-zone (up to $1 \mathrm{~m}$ ) soil moisture data from the simulations conducted with the land surface model (LSM) Hydrology Tiled ECMWF Scheme for Surface Exchanges over Land (HTESSEL), which was developed by the European Centre for Medium-Range Weather Forecasts (ECMWF). The meteorological forcing used in WRR1 is the Watch Forcing Dataset ERA-Interim (WFDEI; Weedon et al. 2014) from ECMWF. The spatial resolution of the WRR 1 is $0.5^{\circ} \times 0.5^{\circ}$, and the temporal resolution of the outputs is daily.
The second dataset we used for initial soil moisture conditions contains the four-layer soil moisture data generated by the Global Land Data Assimilation System (GLDAS; Rui and Beaudoing 2017; Rodell et al. 2004). This dataset is derived from the Noah model version 3.3 in Land Information System (LIS) version 7 . The data are at $0.25^{\circ}$ resolution and range from the year 2000 to the present at a temporal resolution of $3 \mathrm{~h}$. The forcing dataset combines atmospheric analysis fields from the National Oceanic and Atmospheric Administration/National Centers for Environmental Prediction's Global Data Assimilation System (GDAS) with spatially and temporally disaggregated precipitation fields from the Global Precipitation Climatology Project (GPCP) and observationbased downward shortwave and longwave radiation fields derived using the method of the Air Force Weather Agency's Agricultural Meteorological modeling system (AGRMET).

To evaluate the soil moisture fields used as initial conditions in this study, we used as reference the satellitederived European Space Agency Climate Change Initiative (ESA CCI) Surface Soil Moisture (SM) dataset (product version 02.2; Liu et al. 2012). The ESA CCI SM v02.2 product consists of three surface soil moisture datasets. In this study we used the combined product that merges scatterometer-based active and radiometer-based passive soil moisture retrievals (Liu et al. 2011, 2012; Wagner et al. 2012). The spatial resolution of the dataset is $0.25^{\circ}$, and the temporal resolution is 1 day, with its reference time at 0000 UTC. The ESA CCI SM is a stateof-the-art product that has been evaluated using groundbased observations over France (among other regions) by Dorigo et al. (2015) and Liu et al. (2011). In both studies, the merged soil moisture dataset, which is used here as reference, has been evaluated against ground-based soil moisture observations from the soil moisture observing system-meteorological automatic network integrated application (SMOSMANIA) network in southern France. The temporal extent of the evaluation in the first study was 2007-10, and for the second study was January-December 2007. Liu et al. (2011) found an average correlation coefficient $R$ of 0.67 . Dorigo et al. (2015) found a correlation coefficient up to 0.71 (and an average of 0.44 ).

As reference data for the evaluation of the simulated precipitation for the 2002 event, we used data from the Hydrometeorological Data Resources and Technologies for Effective Flash Flood Forecasting (HYDRATE) project (http://www.Hydrate.tesaf.unipd.it/; Borga et al. 2011; Gaume et al. 2009). The rainfall data, derived from a compilation of radar reflectivity observations and rain gauge measurements, have 1-km spatial and 30-min 


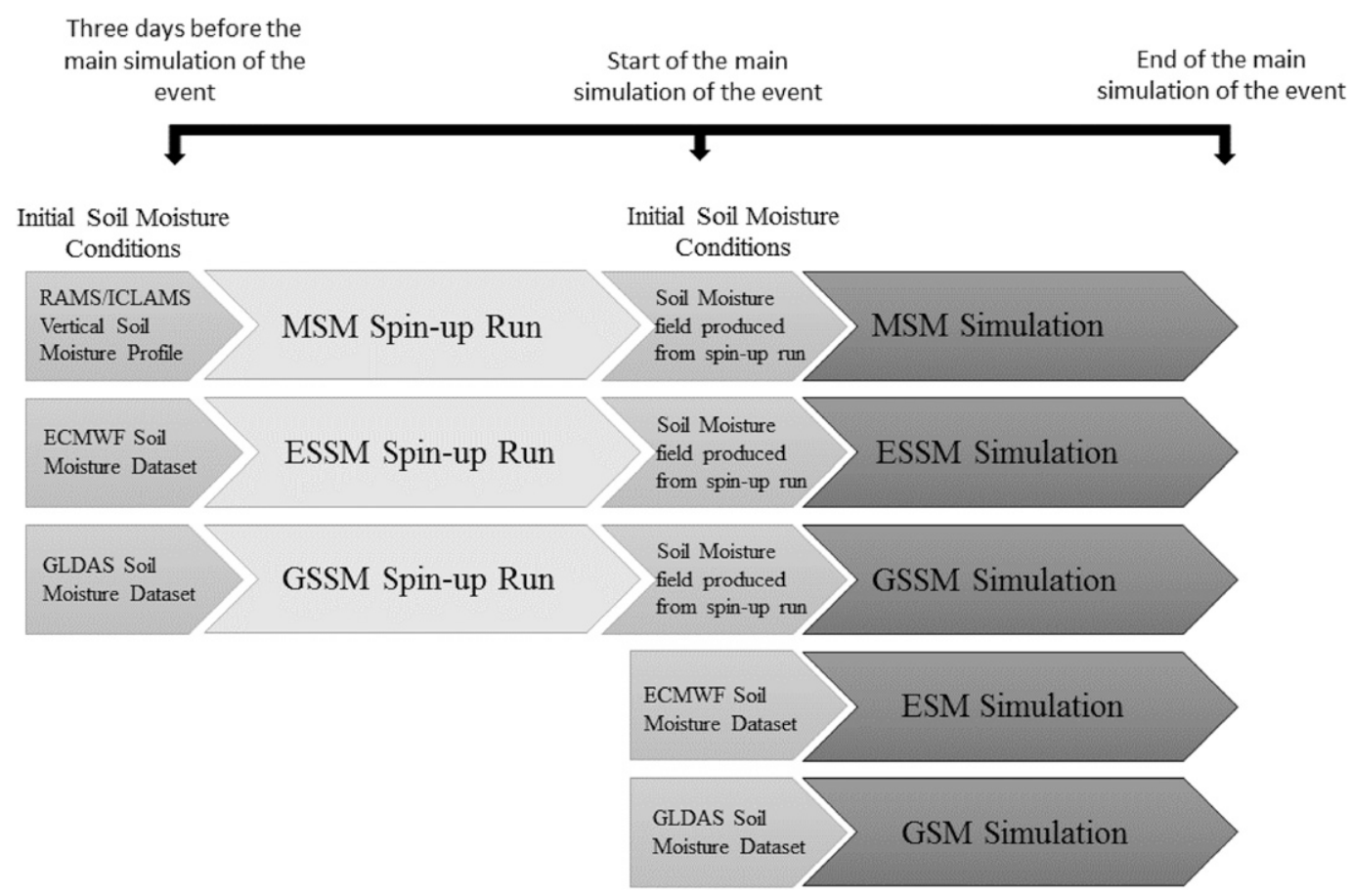

FIG. 2. Schematic representation of the structure of the simulations.

temporal resolution. For the other events, we used the rainfall reanalysis, available at $1-\mathrm{km}$ spatial and hourly temporal resolution, based on radar-rain gauge merging in the Cévennes-Vivarais region of France described in Delrieu et al. (2014) and Boudevillain et al. (2016).

\section{Methodology}

To investigate the sensitivity of convective precipitation to the initial soil moisture field, we conducted five simulation scenarios (one control simulation and four sensitivity tests) for each event with different initial soil moisture conditions (see Fig. 2 for a schematic representation of these simulations). All five simulations of each event started around $12 \mathrm{~h}$ before the initiation of convective precipitation. We performed three of them with 3-day spinup runs, referred to in Fig. 2 as the ESSM (ECMWF spinup soil moisture), GSSM (GLDAS spinup soil moisture), and MSM (model soil moisture; control run) runs; these simulations used, respectively, ECMWF, GLDAS, and a spatial homogeneous initial soil moisture field (i.e., RAMS/ICLAMS default initial soil moisture vertical profile). The spinup simulations have been conducted in order to produce for each simulation a soil moisture field, depending on the meteorological conditions (precipitation and air temperature) and soil characteristics (e.g., hydraulic conductivity) of the study area that would provide a more realistic spatial representation than that provided by the low-spatial-resolution datasets used as initial soil moisture conditions. During this 3-day spinup timeframe, the soil moisture field was altered as a result of model simulation, reducing (smoothing out) the high spatial gradients of soil moisture present in the initial field due to the coarse resolution of the datasets used as initial conditions (ECMWF and GLDAS). Moreover, for the simulation in which the default initial soil moisture conditions have been used, the spinup simulation reduced the homogeneity of the field. The soil moisture fields corresponding to the last hour of the spinup were used as initial soil moisture conditions for the three simulations of the event.

We also considered two additional simulations without spinup (cold start simulations) to be able to evaluate the impact of initial soil moisture resolution on convection. As shown in Fig. 2, these simulations used as initial conditions the ECMWF and GLDAS soil moisture datasets (ESM and GSM, respectively).

In each scenario considering external soil moisture data input (e.g., ECMWF or GLDAS), a two-step procedure is carried out to prepare the initial soil moisture field for the atmospheric simulations. First, LEAF-3 reads the soil moisture values from each dataset and interpolates the value to the spatial resolution of each domain. Second, the interpolated soil moisture data values are compared to the predefined soil type characteristics 
TABLE 1. Schematic representation of the contingency table.

\begin{tabular}{ccc}
\hline & Simulation $<$ threshold & Simulation $\geq$ threshold \\
\hline Observation $<$ threshold & $a$ & $b$ \\
Observation $\geq$ threshold & $c$ & $d$ \\
\hline
\end{tabular}

and are adjusted accordingly. More specifically, the LEAF-3 setup has predefined saturation volumetric moisture content values (thresholds) for each soil type considered. For each grid point, if the soil moisture value derived from the datasets is higher than the threshold value, their value is taken equal to the saturation volumetric moisture content. An important note here is that for the analysis carried out in this work, we considered as initial soil moisture fields the fields that resulted after the two-step process described above. This ensures consistency in the evaluation of differences between initial soil moisture conditions.

Although we applied the different initial soil moisture conditions over all three model domains, we extracted the simulated precipitation values, to perform the statistical analysis of the current work, from the innermost high-resolution $(1 \mathrm{~km})$ domain, which covers the area where the convective precipitation initiated and evolved. It is anticipated that the precipitation over the inner nested domain is affected not only by the modified soil moisture field of the area covered but also from changes in heat fluxes in the parent domains that are transmitted to the nested domain as lateral forcing. Moreover, although the soil moisture content varied up to a depth of $1 \mathrm{~m}$, we based the comparison on the surface soil moisture (first $5-\mathrm{cm}$ depth), given that the satellite could not provide information for deeper soil layers. Furthermore, because of the short duration of the simulations, it is expected that only the surface layer (0-5-cm depth) directly affect the soil moisture-convective precipitation feedback mechanism (Mei and Wang 2011).

For the analysis of the simulations, we initially performed a statistical evaluation of the simulated rain fields to ensure that the control simulations represented the precipitation events realistically. The analyzed time window for this evaluation is the $24 \mathrm{~h}$ with the highest rainfall rate for each event (included in Table 2). The comparison between the simulated and observed precipitation fields was conducted on four temporal scales: $1,6,12$, and $24 \mathrm{~h}$. For performance metrics we chose the bias (Bias) and the square of the correlation coefficient $R^{2}$ defined as follows:

$$
\operatorname{Bias}=\frac{1}{N} \sum_{i=1}^{N}\left(\operatorname{Sim}_{i}-\mathrm{Obs}_{i}\right)
$$

$$
R^{2}=1-\frac{\sum_{i=1}^{N}\left(\mathrm{Obs}_{i}-\mathrm{Sim}_{i}\right)^{2}}{\sum_{i=1}^{N}\left(\mathrm{Obs}_{i}-\overline{\mathrm{Obs}}\right)^{2}},
$$

where $N$ is the number of the grid points multiplied with the number of time steps (total number of observations), Sim is the simulations, Obs is the observations, and $\overline{\mathrm{Obs}}$ is the mean value of the observations.

Moreover, we present three statistical scores computed from contingency tables (Table 1) determined for three thresholds and each temporal scale. These thresholds are based on the 70th, 80th, and 90th quantiles of the probability distribution of the observed rainfall fields for each temporal scale. The statistical scores presented in this study are the forecast accuracy (ACC), the false alarm ratio (FAR), and the frequency bias (FBIAS; Mason 1989), calculated as follows:

$$
\begin{aligned}
\mathrm{ACC} & =\frac{(a+d)}{(a+b+c+d)}, \\
\mathrm{FAR} & =\frac{b}{(b+d)}, \quad \text { and } \\
\text { FBIAS } & =\frac{(b+d)}{(c+d)} .
\end{aligned}
$$

In addition to the point-by-point verification of the rainfall fields, a further analysis using the neighborhood approach technique (Roberts and Lean 2008; Schwartz et al. 2009) is presented in terms of fraction skill scores (FSSs) for a number of different radii and rainfall threshold values. We used five different radius values $(0,1,2,5$, and $10 \mathrm{~km})$ and from four to six rainfall threshold values depending on the total accumulated precipitation values of each event.

We present the results of the comparison of the different simulation scenarios in various forms. First, maps of the differences in accumulated precipitation and initial soil moisture between the simulations and the reference datasets (radar rainfall and satellite soil moisture estimates) provide an overview of the different spatial distributions of precipitation and the water content of the soil. A quantitative analysis, which includes quantilequantile $(\mathrm{Q}-\mathrm{Q})$ plots from the model and radar rainfall 
TABLE 2. Statistical evaluation of the three precipitation events.

\begin{tabular}{|c|c|c|c|c|c|c|c|c|}
\hline \multirow[b]{2}{*}{ Accumulation time step } & \multicolumn{2}{|l|}{$1 \mathrm{~h}$} & \multicolumn{2}{|l|}{$6 \mathrm{~h}$} & \multicolumn{2}{|l|}{$12 \mathrm{~h}$} & \multicolumn{2}{|l|}{$24 \mathrm{~h}$} \\
\hline & Bias (mm) & $R^{2}$ & Bias (mm) & $R^{2}$ & Bias (mm) & $R^{2}$ & Bias (mm) & $R^{2}$ \\
\hline 1200 UTC 8 Sep to 1200 UTC 9 Sep 2002 & -0.9 & 0.04 & -5.6 & 0.16 & -11.3 & 0.23 & -22.6 & 0.34 \\
\hline 0600 UTC 1 Nov to 0600 UTC 2 Nov 2008 & 0.7 & 0.12 & 4.9 & 0.27 & 9.3 & 0.42 & 18.5 & 0.61 \\
\hline 0000 UTC 7 Sep to 0000 UTC 8 Sep 2010 & -0.3 & 0.02 & -3.9 & 0.04 & -4.5 & 0.01 & -6.5 & 0.17 \\
\hline 0600 UTC 20 May to 0600 UTC 21 May 2012 & 0.4 & 0.02 & 2.7 & 0.19 & 4.9 & 0.41 & 9.7 & 0.28 \\
\hline
\end{tabular}

accumulation estimates, as well as the model and satellite remotely sensed soil water content, are used to assess the accuracy of the simulated fields of these variables in capturing the observed distribution $(5 \%-$ $95 \%)$. Additional information regarding the relative skill with which each run simulated both the initial soil moisture and the accumulated precipitation (in terms of spatial distribution) is provided through normalized Taylor diagrams (Taylor 2001; Kärnä and Baptista 2016).

To show the impact of initial soil moisture conditions on convection-related variables, we provide plots with the distribution of the relative differences in soil moisture, heat fluxes, convective available potential energy [CAPE; we calculated the CAPE $\left(\mathrm{J} \mathrm{kg}^{-1}\right)$ only for the parcel with maximum equivalent potential temperature in the column], and precipitation between the sensitivity tests and the control run (which in our study is the MSM simulation). These plots provide insight into the response of different convection-related variables to various soil moisture fields. Finally, we investigated the impact of initial soil water content on the microphysical structure of the clouds. These results are presented in plots with the domain-averaged liquid water and ice mixing ratios for each vertical layer of the model.

\section{Results}

In this section we present the results of the different simulation scenarios, beginning with statistical analysis of the model prediction performance, followed by analysis of the impact of soil moisture on convection-related variables.

The results of the statistical evaluation of the simulated rain fields from the control runs (described above) are presented in Tables 2-6. Specifically, Table 2 shows the Bias and $R^{2}$ calculated for the four simulated events for each temporal scale. We note that the model underestimated the rain of the 2002 and 2010 events, while there is overestimation of precipitation of the 2008 and 2012 events. In terms of correlation, the 2008 event exhibited the highest coefficient of determination $R^{2}$ for all temporal scales. On the contrary, the simulation of the 2010 event showed the poorest representation of the spatial distribution of precipitation. It is evident from this table that for the larger temporal scale the simulated rainfall patterns are in closer agreement with the observations.

The scores obtained from the contingency tables are presented in Tables 3-6 for the 2002, 2008, 2010, and 2012 events, respectively, for each temporal scale (1-24h). The ACC values estimated for all four events is higher than 0.64 for all threshold values and temporal scales. These results indicate that the overall accuracy of the rainfall representation from the simulations is relatively high. In most cases the false alarm ratio is higher for the higher threshold values, indicating that the model could not represent accurately the spatial distribution of the higher amounts of rainfall. The FBIAS score is improved with the largest thresholds for the 2002 and 2010 events (due to the underestimation mentioned earlier); however, the opposite is the case for the overestimated events (2008 and 2012). For all four events, the FBIAS score reduces at the largest temporal scale.

Figure 3 shows the FSSs for each rainfall event. It is evident from this plot that the broader the neighborhood radii used for the FSS estimation, the higher is the FSS, especially for high rainfall thresholds. This indicates spatial displacement errors of the simulated precipitation. For all the events, the plots show that the

TABLE 3. Statistical scores for the 2002 precipitation event.

\begin{tabular}{|c|c|c|c|c|c|c|c|c|c|c|c|c|}
\hline \multirow{2}{*}{$\frac{\text { Accumulation time step }}{\text { Thresholds }(\mathrm{mm})}$} & \multicolumn{3}{|c|}{$1 \mathrm{~h}$} & \multicolumn{3}{|c|}{$6 \mathrm{~h}$} & \multicolumn{3}{|c|}{$12 \mathrm{~h}$} & \multicolumn{3}{|c|}{$24 \mathrm{~h}$} \\
\hline & 3.4 & 6.1 & 14 & 26 & 44.5 & 95.4 & 64.3 & 107.8 & 166.7 & 138.9 & 217.9 & 338.5 \\
\hline $\mathrm{ACC}$ & 0.69 & 0.75 & 0.86 & 0.71 & 0.78 & 0.88 & 0.74 & 0.81 & 0.88 & 0.77 & 0.83 & 0.89 \\
\hline FAR & 0.53 & 0.64 & 0.75 & 0.46 & 0.53 & 0.63 & 0.4 & 0.48 & 0.62 & 0.34 & 0.4 & 0.57 \\
\hline FBIAS & 0.75 & 0.81 & 0.85 & 0.85 & 0.88 & 0.72 & 0.76 & 0.75 & 0.87 & 0.7 & 0.71 & 0.78 \\
\hline
\end{tabular}


TABLE 4. As in Table 3, but for the 2008 precipitation event.

\begin{tabular}{|c|c|c|c|c|c|c|c|c|c|c|c|c|}
\hline \multirow{2}{*}{$\frac{\text { Accumulation time step }}{\text { Thresholds }(\mathrm{mm})}$} & \multicolumn{3}{|c|}{$1 \mathrm{~h}$} & \multicolumn{3}{|c|}{$6 \mathrm{~h}$} & \multicolumn{3}{|c|}{$12 \mathrm{~h}$} & \multicolumn{3}{|c|}{$24 \mathrm{~h}$} \\
\hline & 2 & 3.8 & 7.4 & 18.3 & 31 & 50.9 & 33.8 & 56.3 & 95.2 & 68.3 & 105.2 & 182.8 \\
\hline $\mathrm{ACC}$ & 0.75 & 0.81 & 0.87 & 0.78 & 0.8 & 0.83 & 0.8 & 0.82 & 0.87 & 0.81 & 0.87 & 0.88 \\
\hline FAR & 0.42 & 0.48 & 0.64 & 0.4 & 0.5 & 0.72 & 0.37 & 0.46 & 0.6 & 0.36 & 0.37 & 0.56 \\
\hline FBIAS & 1.06 & 1.08 & 1.24 & 1.27 & 1.33 & 1.55 & 1.32 & 1.35 & 1.47 & 1.26 & 1.25 & 1.45 \\
\hline
\end{tabular}

model has a higher skill for the lower rainfall amounts, while the FSSs for the higher precipitation thresholds are lower for all the events. This suggests that the simulation quality degraded at higher precipitation amounts.

These results show that, while the model simulations exhibited certain limitations mainly in terms of the spatial distribution, the representation of precipitation fields is realistic and the overall performance is comparable (better in some cases) to past studies of the same events (Anquetin et al. 2005). Therefore, we consider that the control simulation has an acceptable performance that allows us to continue with the sensitivity study.

Subsequently, we compared the simulated initial soil moisture field with the satellite remotely sensed soil water content. Figures 4 and 5 provide respective soil moisture maps for the 2002 event (the most extreme) and the 2010 event (with high spatial variability both in convective precipitation and soil moisture), while Fig. 6 compares the spatial distribution of soil moisture for all four events with the use of quantile-quantile plots. Notable in Figs. 4 and 5 are the differences among the initial soil moisture fields in terms of magnitude and spatial distribution. Simulated initial soil moisture is generally lower than the satellite-retrieved soil moisture magnitudes in most of the sensitivity tests. As shown in Fig. 6, soil moisture content in the simulations driven by ECMWF initial conditions was systematically overestimated for most of the events. Similarly, underestimation occurred in the MSM sensitivity tests for all the events. The quantilequantile comparisons indicate that, in most of the cases, the GLDAS-driven soil moisture simulated dataset (GSM simulation) was the one with the closest agreement with the satellite-derived soil moisture data.

The analysis of the sensitivity test shows that the amount of initial soil water content can influence the magnitude and spatial variations of the accumulated precipitation. The results demonstrate a high sensitivity of the numerical simulations to the initial soil moisture fields (see Figs. 7, 8). In contrast to the soil moisture, a common pattern was not apparent among the simulations for the rainfall magnitude. Figure 9 shows the most significant differences in the higher precipitation accumulation values. Comparing the quantile-quantile plots of the two variables, differences in the initial soil moisture evidently resulted in different amounts of simulated precipitation. This is more evident at the upper quantiles of precipitation. Specifically, for the 2002 event, a $39 \%$ change of the domain-averaged initial soil moisture between the MSM and ESSM simulation resulted in $6 \%$ change of the domain-averaged accumulated precipitation. For the 2008 event, a $41 \%$ increase of the initial soil moisture in the ESSM simulation (compared to the MSM simulation) increased by $4.4 \%$ the domainaveraged accumulated precipitation. For the 2010 and 2012 events, the impact of soil moisture is higher on the upper percentiles of the accumulated precipitation. The highest increase of the accumulated precipitation was evident in the 2010 event, where a $35 \%$ increase of soil moisture resulted in a more than $24 \%$ increase of the 90th quantile of accumulated precipitation (between the MSM and ESM simulations). Last, for the 2012 event, a $79 \%$ change of soil moisture between the MSM and ESSM simulation resulted in a $12 \%$ change of the 90th quantile of the accumulated precipitation.

The normalized Taylor diagram, which demonstrates the relative skill with which each run simulated the initial soil moisture and the accumulated precipitation, shows that for the 2002 event, the GSM simulation exhibited the best performance statistics (correlation and root-mean-square error) on both precipitation accumulation and initial soil moisture (Fig. 10a). For this

TABle 5. As in Table 3, but for the 2010 precipitation event.

\begin{tabular}{|c|c|c|c|c|c|c|c|c|c|c|c|c|}
\hline \multirow{2}{*}{$\frac{\text { Accumulation time step }}{\text { Thresholds }(\mathrm{mm})}$} & \multicolumn{3}{|c|}{$1 \mathrm{~h}$} & \multicolumn{3}{|c|}{$6 \mathrm{~h}$} & \multicolumn{3}{|c|}{$12 \mathrm{~h}$} & \multicolumn{3}{|c|}{$24 \mathrm{~h}$} \\
\hline & 1.7 & 4.1 & 8.8 & 32.5 & 45.5 & 67.2 & 52.9 & 67.8 & 91.8 & 94.4 & 124.8 & 162.8 \\
\hline $\mathrm{ACC}$ & 0.71 & 0.78 & 0.86 & 0.71 & 0.75 & 0.82 & 0.64 & 0.7 & 0.82 & 0.68 & 0.79 & 0.89 \\
\hline FAR & 0.49 & 0.57 & 0.73 & 0.48 & 0.65 & 0.9 & 0.61 & 0.78 & 0.96 & 0.54 & 0.55 & 0.56 \\
\hline FBIAS & 0.83 & 0.72 & 0.91 & 0.85 & 0.93 & 0.96 & 0.94 & 0.88 & 0.83 & 0.66 & 0.44 & 0.51 \\
\hline
\end{tabular}


TABLE 6. As in Table 3, but for the 2012 precipitation event.

\begin{tabular}{|c|c|c|c|c|c|c|c|c|c|c|c|c|}
\hline \multirow{2}{*}{$\frac{\text { Accumulation time step }}{\text { Thresholds (mm) }}$} & \multicolumn{3}{|c|}{$1 \mathrm{~h}$} & \multicolumn{3}{|c|}{$6 \mathrm{~h}$} & \multicolumn{3}{|c|}{$12 \mathrm{~h}$} & \multicolumn{3}{|c|}{$24 \mathrm{~h}$} \\
\hline & 0.9 & 2 & 4.7 & 11.6 & 17.5 & 27.2 & 23.3 & 31.3 & 40.6 & 44.3 & 53.5 & 66.8 \\
\hline $\mathrm{ACC}$ & 0.7 & 0.72 & 0.83 & 0.71 & 0.72 & 0.83 & 0.81 & 0.82 & 0.84 & 0.7 & 0.76 & 0.85 \\
\hline FAR & 0.5 & 0.68 & 0.84 & 0.49 & 0.67 & 0.74 & 0.33 & 0.47 & 0.66 & 0.5 & 0.57 & 0.63 \\
\hline FBIAS & 1.05 & 1.06 & 1.15 & 1.08 & 1.21 & 1.51 & 1.06 & 1.3 & 1.9 & 1.18 & 1.36 & 2.05 \\
\hline
\end{tabular}

event, the more accurate initial soil moisture fields in terms of correlation with the satellite product used as observations resulted in improved simulation of precipitation. This was not the case for the 2008 event (Fig. 10b), in which small differences occurred in the model performance for the precipitation simulations, while the initial soil moisture field accuracy differed significantly among the sensitivity tests. Similar behavior was evident in the simulations of the other two events (Fig. 10c for 2010 and Fig. 10d for 2012), although here the precipitation simulations presented slightly larger differences among the sensitivity tests. Results for these cases show that initial soil moisture conditions in closer agreement with the reference dataset do not always result in improved simulations of convective precipitation.
Figure 11 shows the distribution of the relative differences in soil moisture, heat fluxes, CAPE, and precipitation, considering each grid point (time averaged), between the sensitivity tests and the control run (MSM simulation). A point to note from this figure is that the soil moisture had a different effect on convection-related parameters in each event. Furthermore, we observe that the relative differences of CAPE were lower compared to the other variables. However, we report the results because past studies have shown that change in soil conditions is expected to impact the boundary layer conditions and thus CAPE. There are studies that stated that drier boundary layer (resulted from dryer soil) will result in lower CAPE values (Khodayar and Schädler 2013), and other studies that stated the opposite
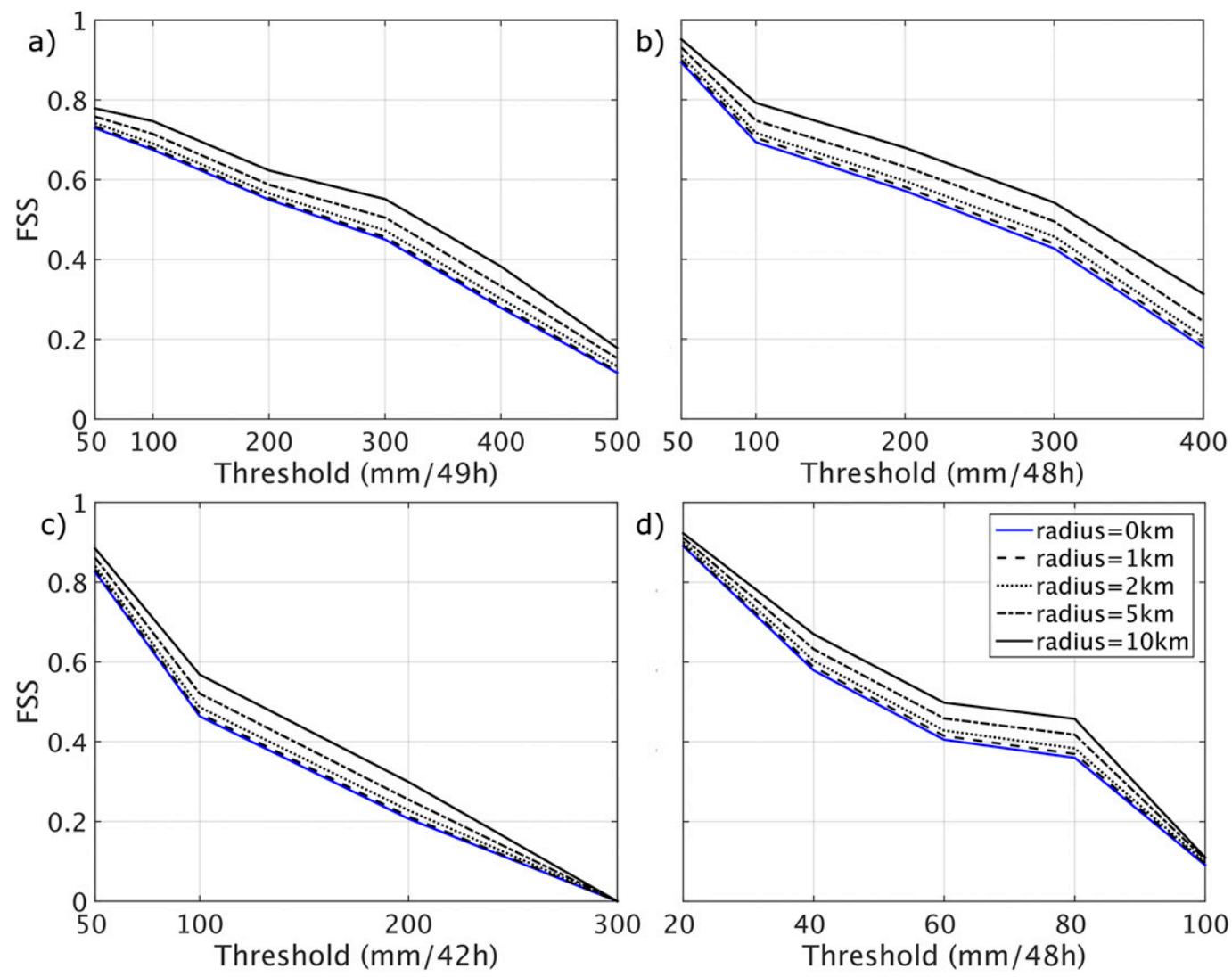

FIG. 3. FSS scores of the simulated precipitation fields for a number of total rainfall thresholds and radius values, for the (a) 2002, (b) 2008, (c) 2010, and (d) 2012 events. 

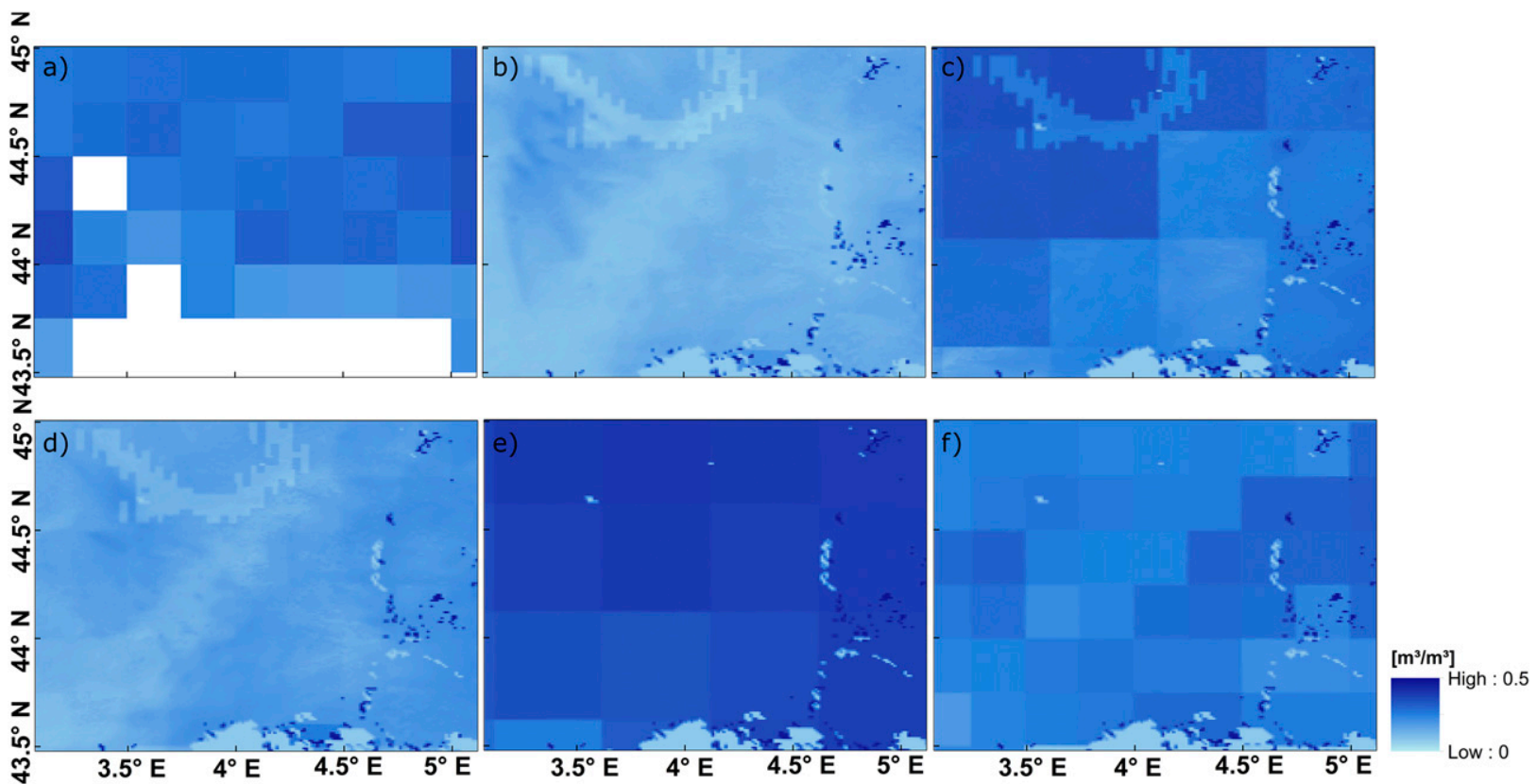

FIG. 4. Initial soil moisture field of the 2002 rainfall event at the start of the main simulations: (a) satellite observations, (b) MSM simulation, (c) ESSM simulation, (d) GSSM simulation, (e) ESM simulation, and (f) GSM simulation. White is missing data.

(Barthlott and Kalthoff 2011). Another notable piece of information provided from Fig. 11 is that the distribution of the relative differences of the variables under consideration is similar between the wet and the dry simulations for each event. For the 2002 event, in particular, although the relative differences of soil moisture seem to be higher in the GSM simulation, the two wet simulations (ESM and ESSM) exhibited higher relative differences in precipitation. For this event, it seems that sensible heat flux was the most affected variable from the differences among the initial soil moisture fields.

Contrary to the 2002 event, in the 2008 event the different initial soil moisture fields affected the latent heat flux more. This might be attributed to the fact that
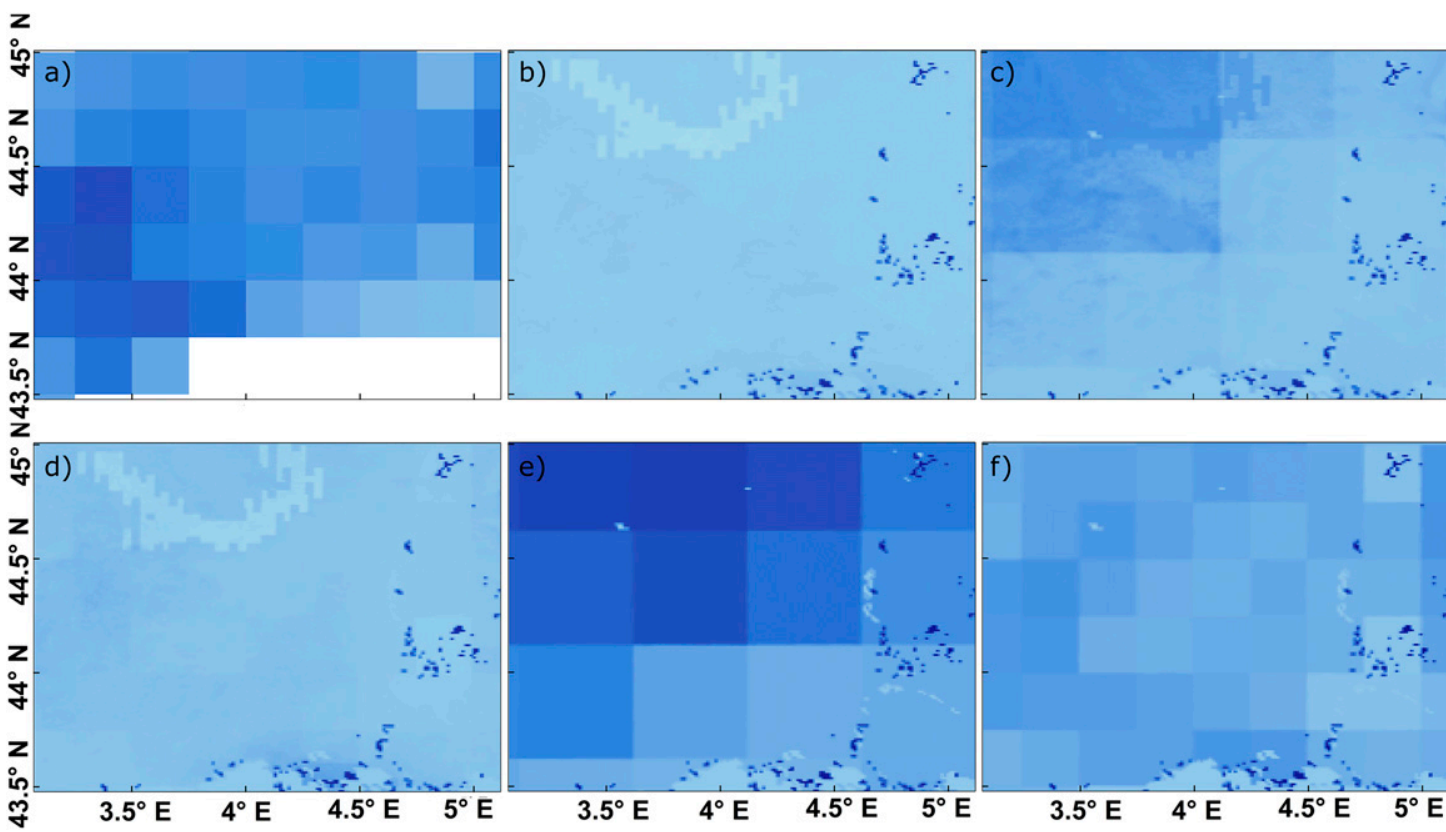

$\left[\mathrm{m}^{3} / \mathrm{m}^{3}\right]$

FIG. 5. As in Fig. 4, but for the 2010 rainfall event. 

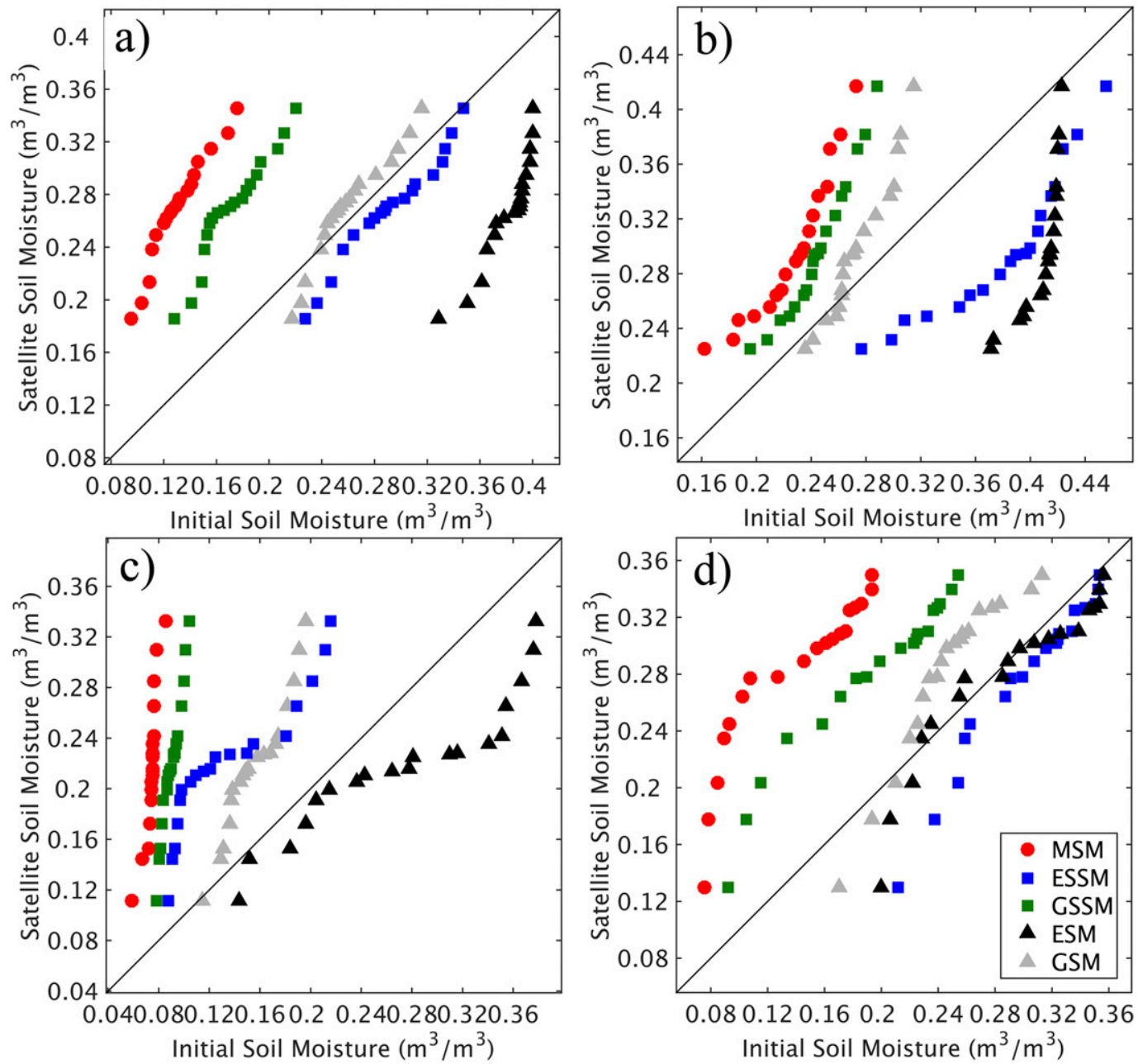

FIG. 6. Quantile-quantile plots of initial soil moisture field used in the simulation of the (a) 2002, (b) 2008, (c) 2010 and (d) 2012 rainfall events, for each model sensitivity test.

the specific humidity in the first event (2002) is higher than the 2008 event; therefore, in the first case the vapor supply to an already humid atmosphere (from the land surface) through latent heat flux had a lower impact than in the second case. Moreover, we observed different behavior in the simulations with spinup runs (ESSM and GSSM) from the ones with cold starts (ESM and GSM) in the relative differences of the fluxes. For the cold start simulations, the impact of soil moisture on the fluxes is higher than in the other simulations. Similar to the 2002 event, for the two simulations with wetter soil conditions (ESSM and ESM), the relative differences of precipitation were significantly higher than in the other simulations. Furthermore, we noticed that these two simulations (ESSM and ESM) exhibited similar patterns of latent heat relative differences for the upper quantiles.

In the 2010 event, similar to the 2002 event, the different initial soil moisture fields affected the sensible heat flux more. The highest relative differences in sensible heat flux were exhibited in the GSSM simulation, where the initial soil moisture was low. The relative differences of precipitation were higher in the wetter simulations. For the 2012 event, initial soil moisture seemed to have had an impact on all variables. In all the sensitivity tests, the higher the initial soil moisture was, the higher were the relative differences of both precipitation and heat fluxes.

As Cioni and Hohenegger (2017) and Schlemmer et al. (2012) pointed out, surface fluxes may affect the ice and liquid water mixing ratio of the clouds. To understand the impact of soil moisture on the convection process, we examined the vertical structure of each system. Figure 12 shows two of the variables that are considered important indicators of the vertical development of a convective system - that is, water vapor and ice mixing ratio. Initial soil moisture strongly influenced the vertical 


\section{2 \\ z}
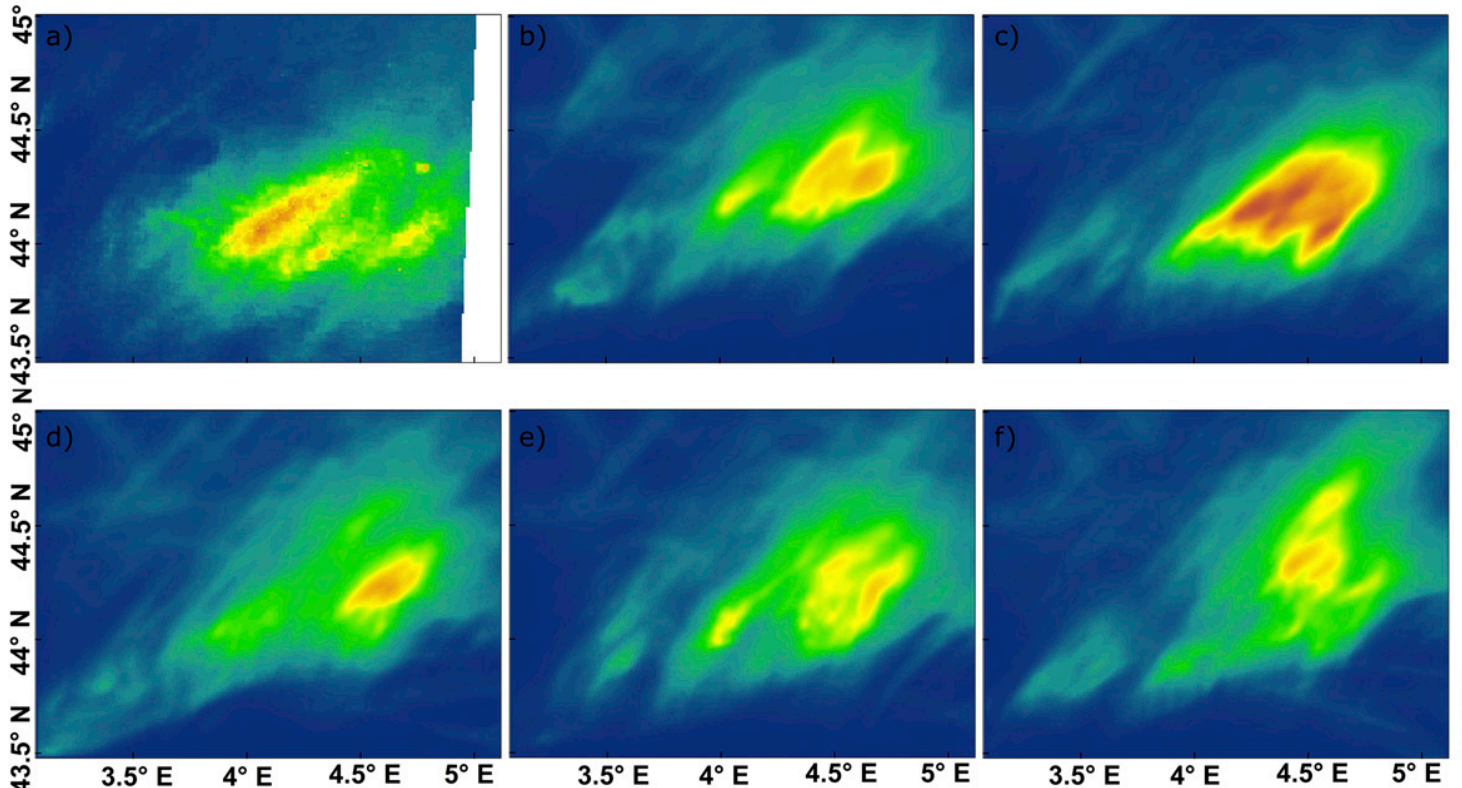

[mm/49h]

FIG. 7. The 49-h accumulated precipitation of the 2002 rainfall event: (a) radar observations, (b) MSM simulation, (c) ESSM simulation, (d) GSSM simulation, (e) ESM simulation, and (f) GSM simulation.

structure of all four convective systems. Based on the results, it is evident that the different initial soil moisture fields influenced the total condensate mixing ratio and the way in which this was partitioned into liquid water and ice mixing ratios. The largest differences were observed in the liquid water mixing ratio among the sensitivity tests of the less severe rainfall events $(2010$ and
2012). These differences were more significant between 2.5 and $4.7 \mathrm{~km}$ altitude for the 2010 event, while for the 2012 event the maximum differences were observed at lower altitudes-that is, $1-2.5 \mathrm{~km}$. In both events, the GSSM was the simulation with the lower liquid water mixing ratio, while maximum amounts were observed in the ESM simulation for the 2010 and the ESSM
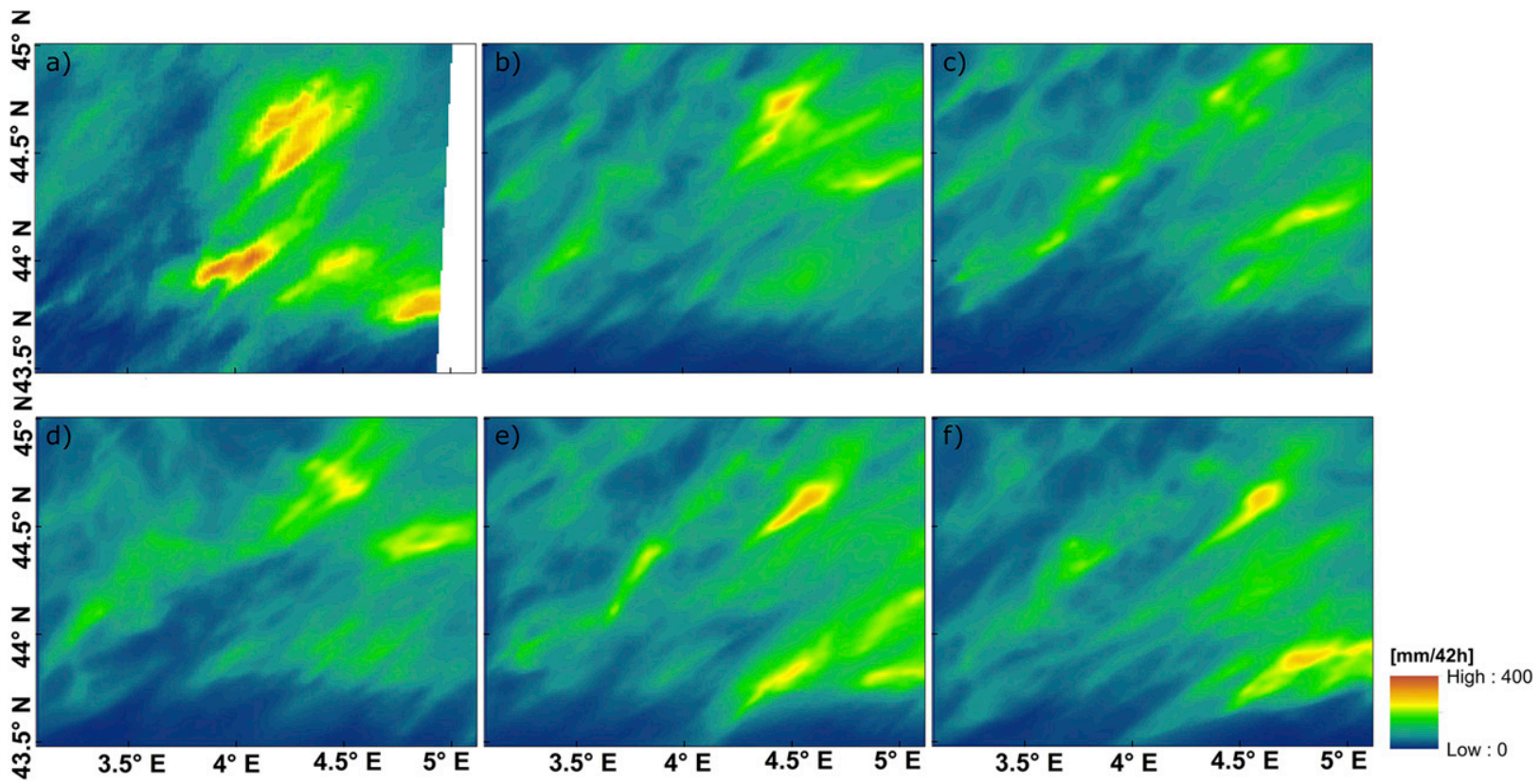

FIG. 8. As in Fig. 7, but for the 2010 rainfall event. 

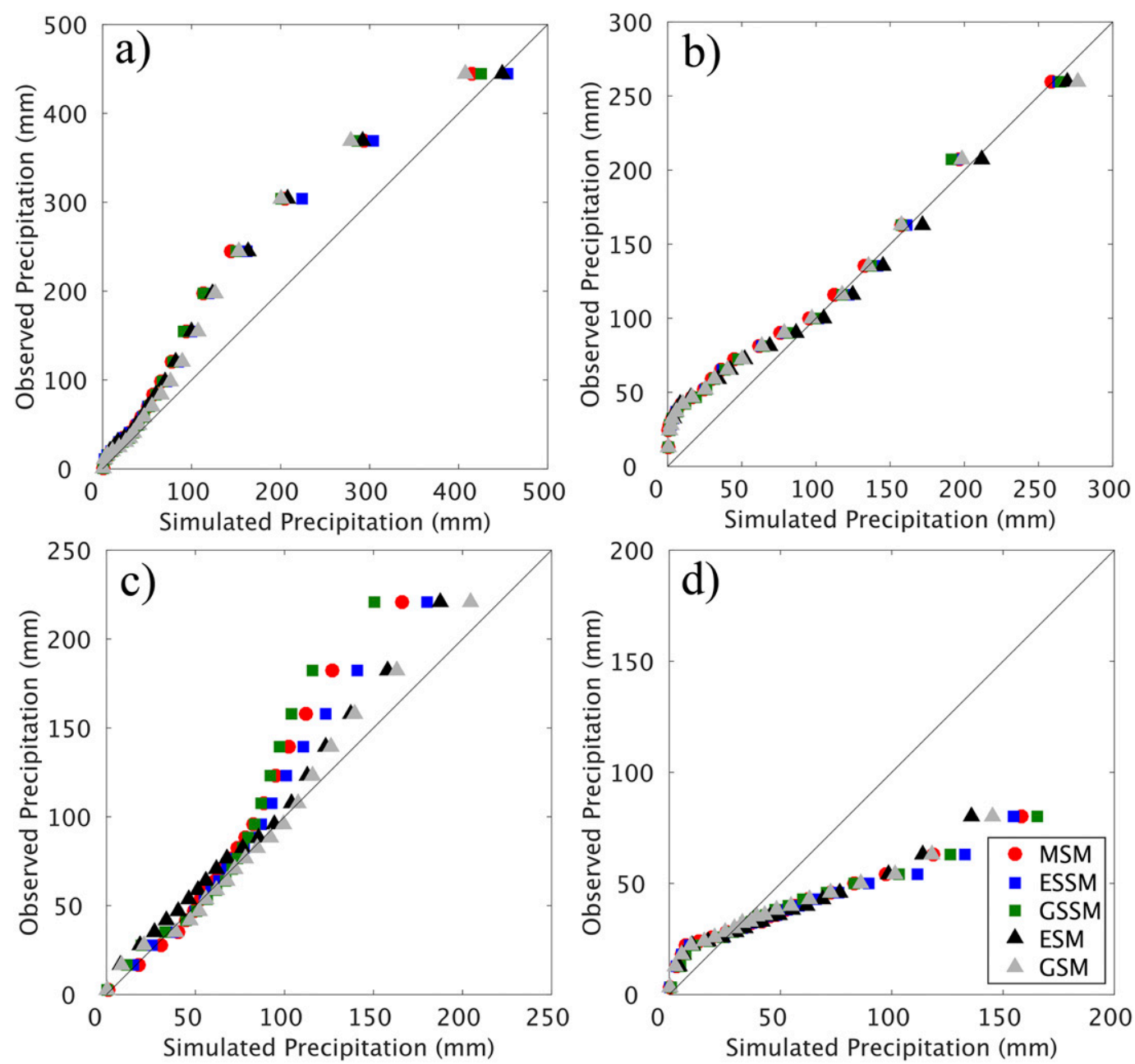

FIG. 9. Quantile-quantile plots of accumulated precipitation for the (a) 2002, (b) 2008, (c) 2010, and (d) 2012 rainfall events, for each model sensitivity test.

simulation for the 2012 events. On the other hand, for the heavier precipitation events in 2002 and 2008, the differences in the liquid water mixing ratio among simulations were less significant.

The ice mixing ratio was used to demonstrate the differences in vertical development among the events and sensitivity tests. The 2002 and 2010 events had the highest vertical development, and the mildest event (2012) had the lowest. For the 2002 event, the ice mixing ratio for the ESSM simulation was significantly higher than for the other sensitivity tests. For the 2008 event, the ice mixing ratio for the GSSM and, especially, the MSM simulations were significantly lower than the other three sensitivity tests. Similar behavior was observed for the 2010 event: the ice mixing ratios for the GSSM and ESSM simulations were lower than for the other three runs. For the milder event, the ice mixing ratio was lower than for the other events, but the relative differences among the different simulations were large.

\section{Discussion and conclusions}

In this study, we designed a numerical experiment to advance the understanding of the relationship between soil moisture and convective precipitation under different meteorological conditions. The experiment included analysis of the sensitivity of weather simulations to different initial soil moisture conditions, in terms of magnitude and spatial distribution. The simulations were performed for four convective precipitation events that differ in terms of triggering mechanisms and synoptic conditions.

Results from this numerical experiment elucidate the complex feedback mechanism between initial soil moisture and convective precipitation. Although we did not 

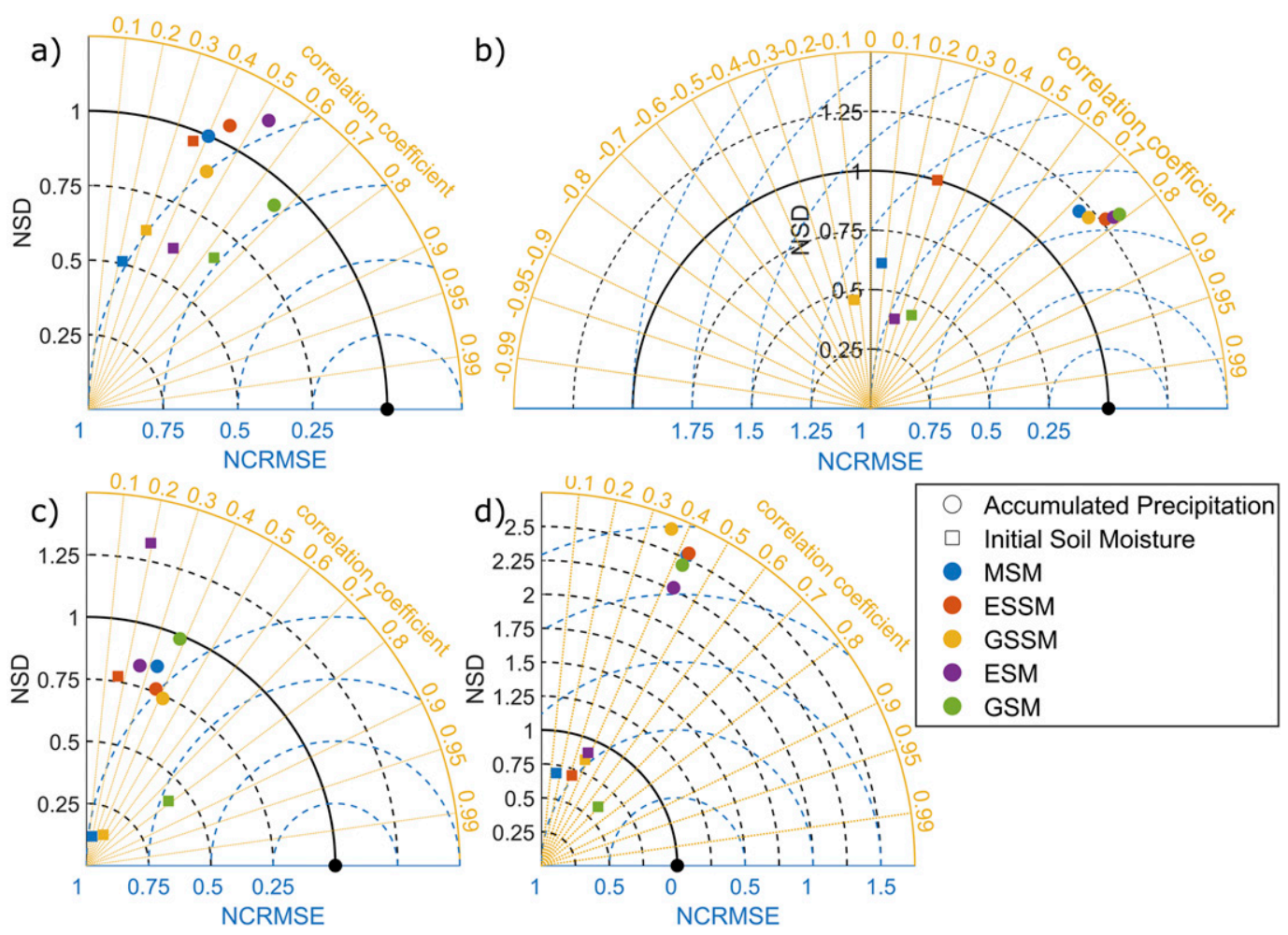

FIG. 10. Normalized Taylor diagram of accumulated precipitation (circles) and initial soil moisture (squares) for the (a) 2002, (b) 2008, (c) 2010, and (d) 2012 rainfall events. The normalized standard deviation is on the radial axis and the correlation coefficient is on the angular axis. The blue dashed lines indicate center root-mean-square error. The black circle is the observed time series (reference).

observe a consistent feedback pattern (in terms of the sign and the magnitude of the relationship) between soil moisture and precipitation for all the case studies, different initial soil moisture fields resulted in different accumulated convective precipitation fields, in terms of both magnitude and spatial distribution. Initial soil water content seems to have a strong impact on the simulation of convective precipitation, not only during mild events, but also in extreme rainfall events with strong synoptic forcing.

The results show that the initial soil moisture field in closer agreement with the satellite-derived soil moisture (used as reference) does not always improve the simulation of convective precipitation. This can be partly attributed to the relatively low spatial resolution of both the observed and simulated soil moisture datasets used as initial conditions. However, $25 \mathrm{~km}$ was the highest spatial resolution of available global daily soil moisture data (covering the temporal extent of our events). Small-scale soil moisture variability (not represented in these low-resolution data), though, can affect local lowlevel circulation and thus the simulation of precipitation (Panegrossi et al. 2011). For the 2002 heavy precipitation event, which was caused by a quasi-stationary
MCS, better representation of initial soil moisture improved the simulation of convective precipitation. Moreover, for the 2008 event, which was also caused by deep convection that affected the area for a long period, initial soil moisture fields that were in good agreement with the reference data resulted in simulated precipitation with higher correlation to observations. On the other hand, for the two events of shorter duration (2010 and 2012), the accuracy of the initial soil moisture field did not affect the relative skill of simulated precipitation. These findings suggest that a better representation of the initial soil moisture field can improve the simulation of convective precipitation when the simulated convective system persists locally over a long period and is strongly affected by local circulation (the local water vapor recycle-the contribution of the local evapotranspiration of some region on precipitation at any point within the same region; Eltahir and Bras 1994; Eltahir 1996).

The analysis of the different sensitivity tests highlighted the complicated nature of the relationship between soil moisture and convective precipitation, which is consistent with the varying results of previous studies on the soil moisture-precipitation feedback mechanism. 

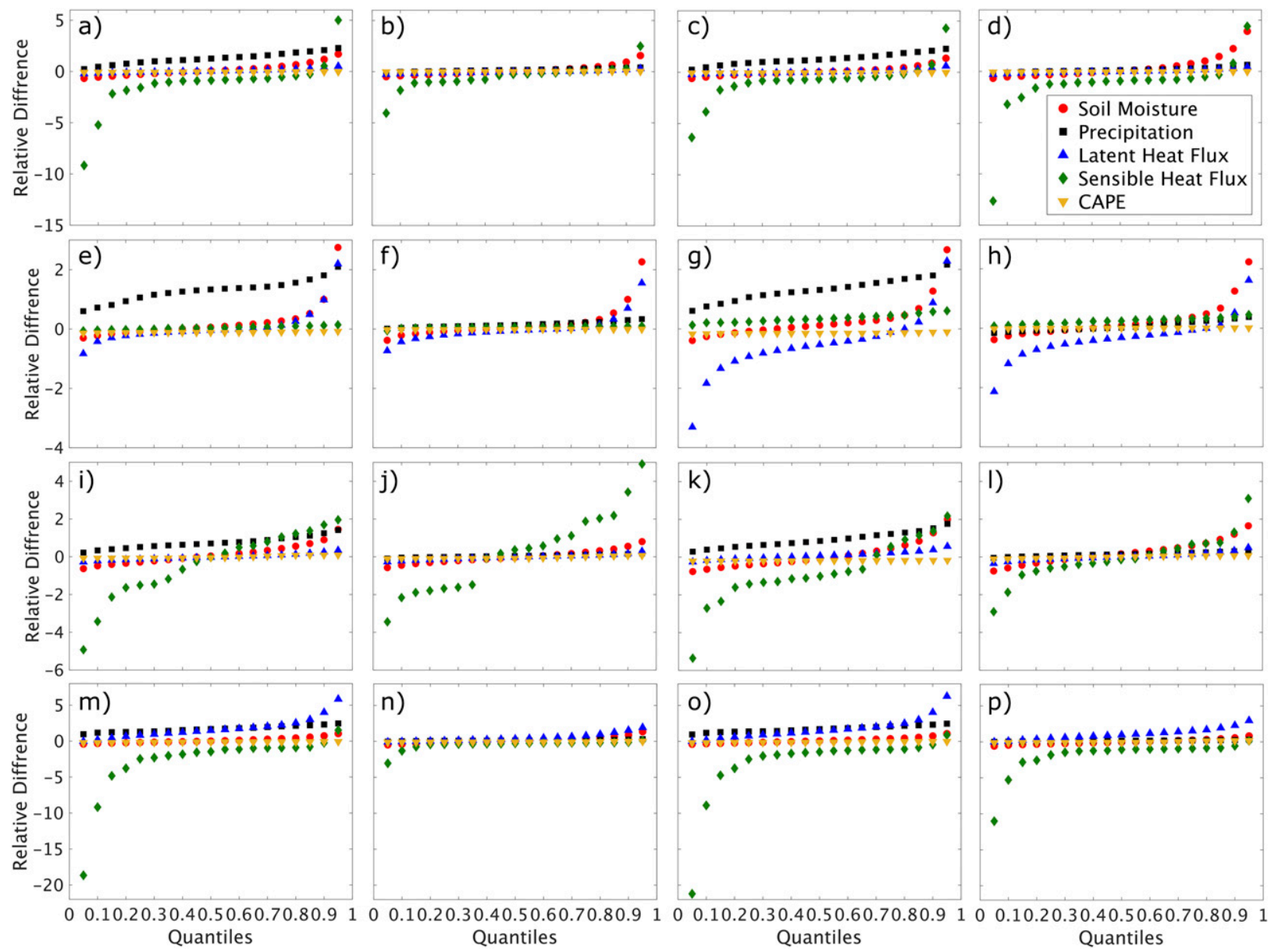

FIG. 11. Quantile-quantile plots of relative differences of hourly precipitation, soil moisture, latent and sensible heat fluxes, and CAPE between the control run (MSM simulation) and the four sensitivity tests (ESSM, GSSM, ESM, and GSM) for the (a)-(d) 2002, (e)-(h) 2008, (i)-(l) 2010, and (m)-(p) 2012 rainfall events.

Although a systematic relationship exists between heat fluxes and the different initial soil moisture fields, no common response of precipitation to these changes in soil moisture conditions is apparent.

Further analysis of the sensitivity tests identified different feedback mechanisms for these variables. In some cases (i.e., the 2002 event for all simulations but the ESM simulation, the ESM and GSM simulations of the 2010 event, and the ESM and ESSM simulations of the 2012 event) wetter soil resulted in more precipitation, while in other simulations (i.e., the ESM simulation of the 2002 event, the GSSM and ESSM simulation of the 2010 event, and the GSSM and GSM simulations of the 2012 event) it caused inhibition of convective precipitation-a finding consistent with the contrasting results of different studies (Guillod et al. 2015; Henneberg et al. 2018; Tuttle and Salvucci 2016) on the soil moisture-precipitation relationship. In most cases, wetter soil resulted in higher latent heat flux, as expected, supplying the atmosphere with water vapor and resulting in intensification of the convective precipitation. However, in some cases [MSM, GSSM, and GSM simulations of the 2002 event; MSM simulations of the 2010 event; and between the drier simulations (MSM and GSSM compared to GSM) simulations of the 2012 event], we identified a negative feedback mechanism between soil moisture and precipitation. Drier soils resulted in higher sensible heat fluxes, intensifying the vertical wind speed (see the appendix) and, thus, the convective precipitation. Our ESM simulation of the 2002 rainfall event showed very high initial soil moisture resulting in lower rainfall compared to the other sensitivity tests of this event; the initial soil moisture seemed to affect the structure of the MCS (in terms of ice and water mixing ratio). The cloud cover ratio was higher than in the other sensitivity tests (not shown), but the amount of precipitation was lower, a possible indication of smaller droplets unable to reach rain droplet size. Moreover, we observe that there is no 

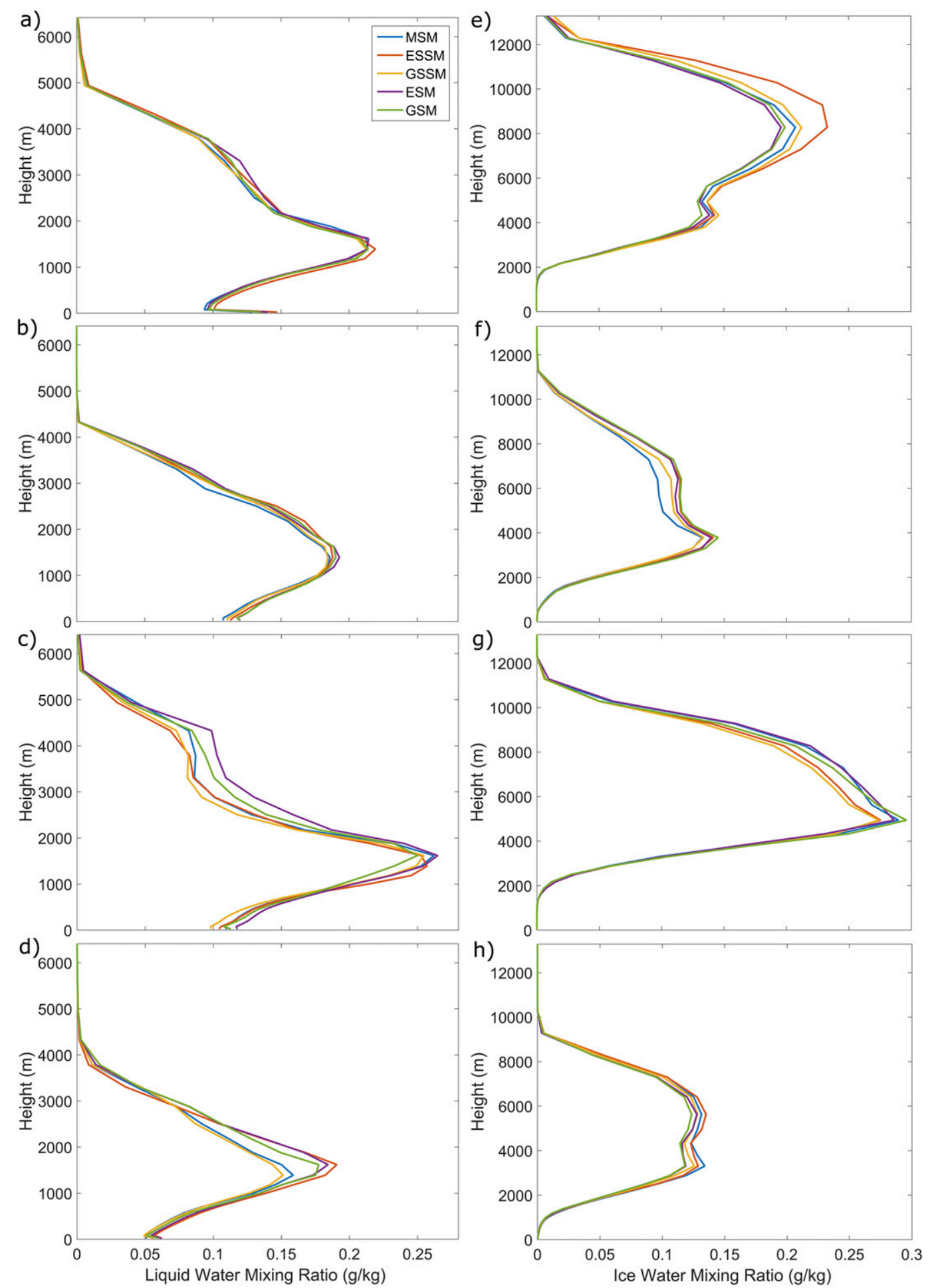

FIG. 12. Vertical profiles of (left) liquid water and (right) ice mixing ratio of each rainfall event: (a),(e) 2002; (b),(f) 2008; (c),(g) 2010; and (d),(h) 2012. 
consistent relationship between soil moisture and CAPE. In some cases, wetter soil resulted in higher CAPE. For example, the wet simulations of the 2002 and 2010 events (ESM, ESSM, and GSM) resulted in higher CAPE (i.e., for the 2002 event a $5.4 \%-7.9 \%$ increase and for the 2010 event a $0.7 \%-4.3 \%$ increase of CAPE compared to the MSM simulation). However, there were simulations, like the sensitivity tests of the 2008 and 2012 events (ESM and ESSM), which exhibited lower values of CAPE (i.e., for the 2008 events up to $23 \%$ and for 2010 events up to $9.4 \%$ lower CAPE compared to the MSM simulation) with higher values of soil moisture. In the first case, wetter soil resulted in a more humid low-level atmosphere and therefore, condensation-associated cooling caused an increased CAPE. We may attribute the negative relationship between soil moisture and CAPE to the upper-level atmospheric temperature. We noticed that the simulations with lower CAPE (despite the wetter soil) exhibited lower liquid and ice mixing ratio and therefore less condensation-associated cooling, which results in lower values of CAPE. Higher CAPE did not always result in higher amounts of precipitation. This may be attributed to the contrasting effects of CAPE and cold pools. Convective cold pools have been identified in the simulations of all four events. As Van Weverberg et al. (2010) explained, the effect of the increased CAPE can be compensated by less intense evaporating coolingrelated cold pools.

Our results showed that the spatial distribution of soil moisture also plays an important role in convective precipitation. As Emori (1998) pointed out, intense spatial contrasts in soil moisture can cause thermally induced local circulation that may modify the prevailing atmospheric conditions. In this study we used three soil moisture datasets with different spatial resolutions. We noticed that when the initial soil moisture field had high gradients (which was usually the case in the GSM simulation due to the higher resolution), the subsequent convective precipitation was enhanced. This was the case for the 2008 event, where the GSM simulation resulted in higher amounts of precipitation compared with the other sensitivity tests of the same event. Similar behavior of precipitation linked to high soil moisture gradients is also reported in Dalu et al. (1991). Moreover, for the cold start simulations of the 2008 event, the impact of soil moisture on heat fluxes (mainly on latent heat flux) was higher. During the three days of the spinup period, the initial soil moisture field was smoothed out relative to the cold start simulations, and thus the range of heat fluxes was lower.

Initial soil moisture had an indirect effect on the convective precipitation process. As mentioned above, soil moisture can affect the microphysical structure of a convective system (as indicated by the liquid water and ice mixing ratios). For the extreme events, the initial soil moisture had a greater effect on the ice mixing ratio than on the liquid water mixing ratio. For these events, the similar behavior (in terms of magnitude) between convective precipitation and ice mixing ratio implied that most of the precipitation was attributable to solid hydrometeors. The GSM simulation of the 2002 rainfall event, however, which resulted in large amounts of precipitation, had lower ice and liquid water mixing ratios than the other sensitivity tests. This is because the solid and liquid hydrometeors in this simulation were fewer in number but big enough to become precipitable water, unlike in the MSM and GSSM simulations, where the mean diameter of the aggregates was smaller (not shown). For the 2010 event, differences occurred among the simulations in both the liquid water and ice mixing ratios, and both ratios were correlated with the accumulated precipitation. Finally, for the mild event, the larger amounts of precipitation for the simulations with wetter soil seemed to come from the lower levels of the atmosphere, while for the driest simulations sensible heat flux intensified the updrafts, and, thus, soil hydrometeors from the upper atmosphere became precipitable water. We noticed that for the two events (2002 and 2010) where soil moisture affected the sensible heat flux more (than the latent heat flux), the impact of soil moisture on ice mixing ratio is higher compared to the other events. This could be because changes in sensible heat flux affected the vertical wind speed, which resulted in changes to the temperature profile of the system. A point to note is that for these two events, sensible heat had the highest impact on the vertical wind speed both in terms of magnitude (see appendix) and temporal evolution (not shown). The initial soil moisture also affected the microphysical structure of the clouds, changing not only the amount of water vapor in the atmosphere, but also the temperature.

The findings of this study demonstrate the complexity of the relationship between soil moisture and convective precipitation, highlighting its nonlinear and nonmonotonic behavior. As Schär et al. (1999) showed, local recycling (of water vapor) alone does not explain the soil moisture-precipitation relationship; water vapor advection also plays an important role in the water budget of the atmosphere. For our study, we changed the initial soil moisture field for all the domains, not only the high-resolution one. Therefore, changes of water vapor in the area under study could also be attributed to the different initial soil moisture condition in the outer domains. However, given that the sustained wind in all four events analyzed in this study are southeast to southwest, this suggests that most of the water vapor 

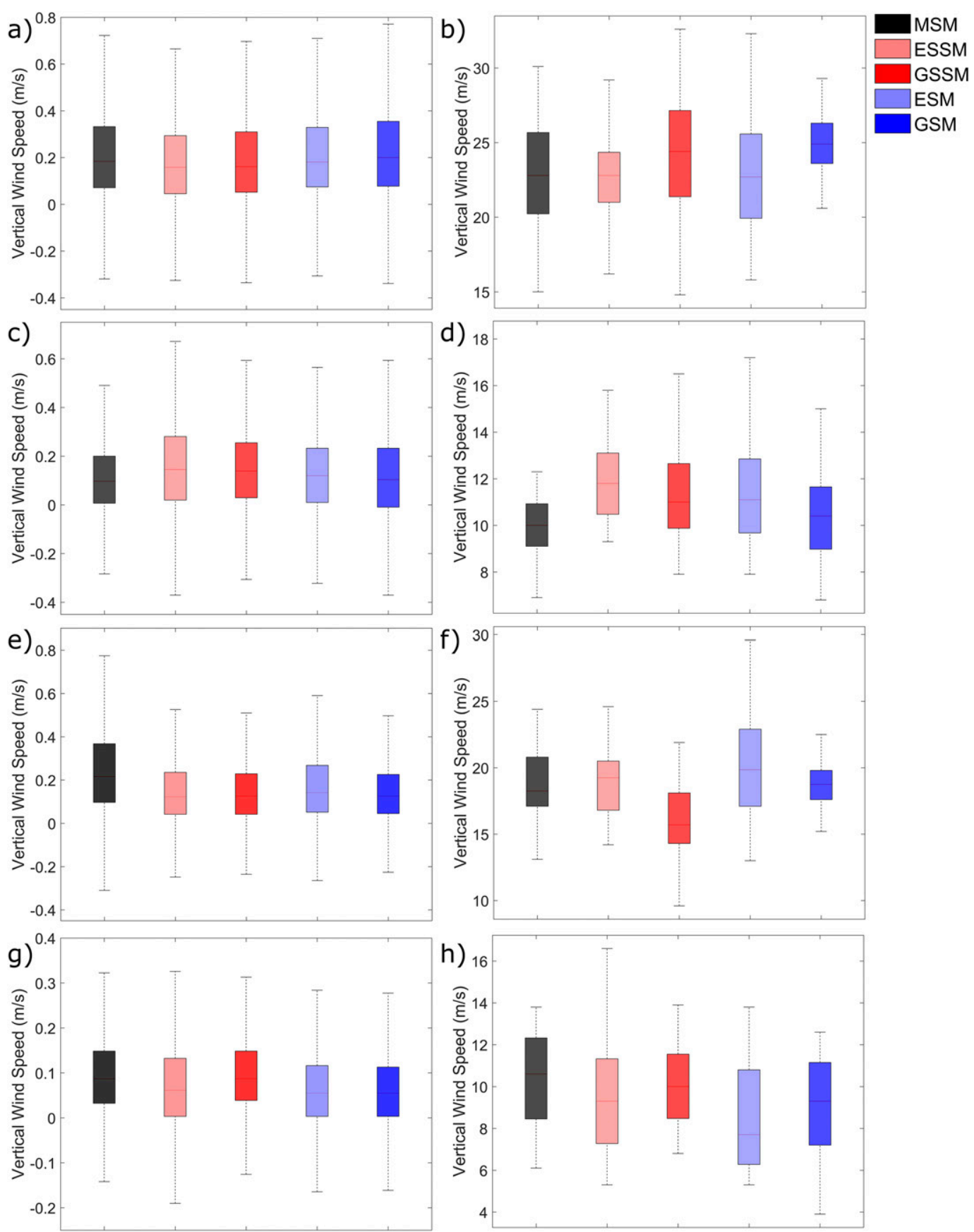

FIG. A1. Box plot of (left) the averaged (of all model layers) and (right) hourly maximum vertical wind speed of each rainfall event: (a),(b) 2002; (c),(d) 2008; (e),(f) 2010; and (g),(h) 2012.

entering the domain through advection from the outer domains comes from the Mediterranean Sea. Thus, significant changes in lateral moisture supply, for the different soil moisture scenarios, are not expected, and we therefore assume that observed changes mostly result from changes in the soil moisture conditions of the high-resolution domain.
These results provide, at least in part, a possible explanation for the contradictory findings in the literature. As mentioned, this study only investigated how convective precipitation is affected locally by soil moisture. Water vapor advection from the outer domains might affect the water budget of the atmosphere and thus the amount of convective precipitation. Our results 
are intended to continue improving the simulation of convective precipitation and advancing our understanding of the physical mechanisms.

Acknowledgments. The authors thank Guy Delrieu and Brice Boudevillain, who provided the rainfall reanalysis data for this study. This research was supported by the FP7 project eartH2Observe (Grant Agreement 603608).

\section{APPENDIX}

\section{Vertical Wind Speed}

We present the box plots (Fig. A1) of the hourly maximum and average vertical wind speed of all the model layers (24-13281 m above ground) of all the events. The vertical wind speed was calculated using a moving window $(50 \mathrm{~km} \times 50 \mathrm{~km})$ around the hourly domain maximum precipitation, to focus only on the convective system. In some events $(2002,2010$, and 2012) a negative feedback mechanism between the soil moisture and precipitation was evident. In some cases, we noted that drier soils intensified the vertical wind speed, which consequentially resulted in enhanced precipitation. These cases are the MSM, GSSM, and GSM simulations of the 2002 event; the MSM simulation of the 2010 event; and the MSM and GSSM simulation of the 2012 events (compared to the GSM event).

\section{REFERENCES}

Adler, B., N. Kalthoff, and L. Gantner, 2011: The impact of soil moisture inhomogeneities on the modification of a mesoscale convective system: An idealised model study. Atmos. Res., 101, 354-372, https://doi.org/10.1016/j.atmosres.2011.03.013.

Anquetin, S., F. Minsicloux, J. D. Creutin, and S. Cosma, 2003: Numerical simulation of orographic rainbands. J. Geophys. Res., 108, 8386, https://doi.org/10.1029/2002JD001593.

- and Coauthors, 2005: The 8 and 9 September 2002 flash flood event in France: A model intercomparison. Nat. Hazards Earth Syst. Sci., 5, 741-754, https://doi.org/10.5194/nhess-5-741-2005.

—, V. Ducrocq, I. Braud, and J. D. Creutin, 2009: Hydrometeorological modelling for flash flood areas: The case of the 2002 Gard event in France. J. Flood Risk Manage., 2, 101-110, https://doi.org/10.1111/j.1753-318X.2009.01023.x.

Barthlott, C., and N. Kalthoff, 2011: A numerical sensitivity study on the impact of soil moisture on convection-related parameters and convective precipitation over complex terrain. J. Atmos. Sci., 68, 2971-2987, https://doi.org/10.1175/JAS-D-11-027.1.

Borga, M., E. N. Anagnostou, G. Blöschl, and J. D. Creutin, 2011: Flash flood forecasting, warning and risk management: The HYDRATE project. Environ. Sci. Policy, 14, 834-844, https:// doi.org/10.1016/j.envsci.2011.05.017.

Boudevillain, B., G. Delrieu, A. Wijbrans, and A. Confoland, 2016: A high-resolution rainfall re-analysis based on radar-raingauge merging in the Cévennes-Vivarais region, France. J. Hydrol., 541, 14-23, https://doi.org/10.1016/j.jhydrol.2016.03.058.
Cheng, W. Y., and W. R. Cotton, 2004: Sensitivity of a cloudresolving simulation of the genesis of a mesoscale convective system to horizontal heterogeneities in soil moisture initialization. J. Hydrometeor., 5, 934-958, https://doi.org/10.1175/ 1525-7541(2004)005<0934:SOACSO > 2.0.CO;2.

Cioni, G., and C. Hohenegger, 2017: Effect of soil moisture on diurnal convection and precipitation in large-eddy simulations. J. Hydrometeor., 18, 1885-1903, https://doi.org/10.1175/ JHM-D-16-0241.1.

Cotton, W. R., and Coauthors, 2003: RAMS 2001: Current status and future directions. Meteor. Atmos. Phys., 82, 5-29, https:// doi.org/10.1007/s00703-001-0584-9.

Dalu, G. A., R. A. Pielke, R. Avissar, G. Kallos, M. Baldi, and A. Guerrini, 1991: Linear impact of thermal inhomogeneities on mesoscale atmospheric flow with zero synoptic wind. Ann. Geophys., 9, 641-647.

Delrieu, G., and Coauthors, 2005: The catastrophic flash-flood event of 8-9 September 2002 in the Gard Region, France: A first case study for the Cévennes-Vivarais Mediterranean Hydrometeorological Observatory. J. Hydrometeor., 6, 34-52, https://doi.org/10.1175/JHM-400.1.

_ , L. Bonnifait, P. E. Kirstetter, and B. Boudevillain, 2014: Dependence of radar quantitative precipitation estimation error on the rain intensity in the Cévennes region, France. Hydrol. Sci. J., 59, 1308-1319, https://doi.org/10.1080/02626667.2013.827337.

Dirmeyer, P. A., A. J. Dolman, and N. Sato, 1999: The pilot phase of the global soil wetness project. Bull. Amer. Meteor. Soc., 80, 851-878, https://doi.org/10.1175/1520-0477(1999)080<0851: TPPOTG $>2.0 . C O ; 2$.

Dorigo, W. A., and Coauthors, 2015: Evaluation of the ESA CCI soil moisture product using ground-based observations. Remote Sens. Environ., 162, 380-395, https://doi.org/10.1016/ j.rse.2014.07.023.

Eltahir, E. A., 1996: Role of vegetation in sustaining large-scale atmospheric circulations in the tropics. J. Geophys. Res., 101, 4255-4268, https://doi.org/10.1029/95JD03632.

— , and R. L. Bras, 1994: Precipitation recycling in the Amazon basin. Quart. J. Roy. Meteor. Soc., 120, 861-880, https://doi.org/ 10.1002/qj.49712051806.

Emori, S., 1998: The interaction of cumulus convection with soil moisture distribution: An idealized simulation. J. Geophys. Res., 103, 8873-8884, https://doi.org/10.1029/98JD00426.

Fresnay, S., A. Hally, C. Garnaud, E. Richard, and D. Lambert, 2012: Heavy precipitation events in the Mediterranean: Sensitivity to cloud physics parameterisation uncertainties. Nat. Hazards Earth Syst. Sci., 12, 2671, https://doi.org/10.5194/ nhess-12-2671-2012.

Fritsch, J. M., and Coauthors, 1998: Quantitative precipitation forecasting: Report of the eighth prospectus development team, US Weather Research Program. Bull. Amer. Meteor. Soc., 79, 285-299, https://doi.org/10.1175/1520-0477(1998) $079<0285$ :QPFROT $>2.0 . C O ; 2$.

Gallus, W. A., Jr., and M. Segal, 2000: Sensitivity of forecast rainfall in a Texas convective system to soil moisture and convective parameterization. Wea. Forecasting, 15, 509-525, https://doi.org/ 10.1175/1520-0434(2000)015<0509:SOFRIA >2.0.CO;2.

Gaume, E., and Coauthors, 2009: A compilation of data on European flash floods. J. Hydrol., 367, 70-78, https://doi.org/10.1016/ j.jhydrol.2008.12.028.

Guillod, B. P., and Coauthors, 2014: Land-surface controls on afternoon precipitation diagnosed from observational data: Uncertainties and confounding factors. Atmos. Chem. Phys., 14, 8343-8367, https://doi.org/10.5194/acp-14-8343-2014. 
- B. Orlowsky, D. G. Miralles, A. J. Teuling, and S. I. Seneviratne, 2015: Reconciling spatial and temporal soil moisture effects on afternoon rainfall. Nat. Commun., 6, 6443, https://doi.org/10.1038/ ncomms 7443 .

Hauck, C., C. Barthlott, L. Krauss, and N. Kalthoff, 2011: Soil moisture variability and its influence on convective precipitation over complex terrain. Quart. J. Roy. Meteor. Soc., 137, 42-56, https://doi.org/10.1002/qj.766.

Henneberg, O., F. Ament, and V. Grützun, 2018: Assessing the uncertainty of soil moisture impacts on convective precipitation using a new ensemble approach. Atmos. Chem. Phys., 18 https://doi.org/10.5194/acp-18-6413-2018.

Hohenegger, C., P. Brockhaus, C. S. Bretherton, and C. Schär, 2009: The soil moisture-precipitation feedback in simulations with explicit and parameterized convection. J. Climate, 22, 5003-5020, https://doi.org/10.1175/2009JCLI2604.1.

Huet, P., X. Martin, J.-L. Prime, P. Foin, C. Laurain, and P. Cannard, 2003: Retour d'expérience des crues de septembre 2002 dans les départements du Gard, de l'Hérault, du Vaucluse, des Bouches-du-Rhône, de l'Ardèche et de la Drôme. Rapport de l'Inspection Générale de l'Environnement, Ministere de l'écologie et du développement durable, 133 pp., https:// www.ladocumentationfrancaise.fr/rapports-publics/034000547/ index.shtml

Kain, J. S., 2004: The Kain-Fritsch convective parameterization: An update. J. Appl. Meteor., 43, 170-181, https://doi.org/10.1175/ 1520-0450(2004)043<0170:TKCPAU > 2.0.CO;2.

_ , and J. M. Fritsch, 1993: Convective parameterization for mesoscale models: The Kain-Fritsch scheme. The Representation of Cumulus Convection in Numerical Models, Meteor. Monogr., No. 46, Amer. Meteor. Soc., 165-170.

Kärnä, T., and A. M. Baptista, 2016: Evaluation of a long-term hindcast simulation for the Columbia River estuary. Ocean Modell., 99, 1-14, https://doi.org/10.1016/j.ocemod.2015.12.007.

Khodayar, S., and G. Schädler, 2013: The impact of soil moisture variability on seasonal convective precipitation simulations. Part II: Sensitivity to land-surface models and prescribed soil type distributions. Meteor. Z., 22, 507-526, https://doi.org/ 10.1127/0941-2948/2013/0431.

Kushta, J., G. Kallos, M. Astitha, S. Solomos, C. Spyrou, C. Mitsakou, and J. Lelieveld, 2014: Impact of natural aerosols on atmospheric radiation and consequent feedbacks with the meteorological and photochemical state of the atmosphere. J. Geophys. Res. Atmos., 119, 1463-1491, https://doi.org/10.1002/2013JD020714.

Liu, Y. Y., R. M. Parinussa, W. A. Dorigo, R. A. De Jeu, W. Wagner, A. I. J. M. Van Dijk, M. F. McCabe, and J. P. Evans, 2011: Developing an improved soil moisture dataset by blending passive and active microwave satellite-based retrievals. Hydrol. Earth Syst. Sci., 15, 425-436, https://doi.org/ 10.5194/hess-15-425-2011.

- W. A. Dorigo, R. M. Parinussa, R. A. de Jeu, W. Wagner, M. F. McCabe, J. P. Evans, and A. I. J. M. Van Dijk, 2012: Trend-preserving blending of passive and active microwave soil moisture retrievals. Remote Sens. Environ., 123, 280-297, https://doi.org/10.1016/j.rse.2012.03.014.

Manus, C., S. Anquetin, I. Braud, J. P. Vandervaere, J. D. Creutin, P. Viallet, and E. Gaume, 2009: A modeling approach to assess the hydrological response of small Mediterranean catchments to the variability of soil characteristics in a context of extreme events. Hydrol. Earth Syst. Sci., 13, 79-97, https://oi.org/ 10.5194/hess-13-79-2009.

Mason, I., 1989. Dependence of the critical success index on sample climate and threshold probability. Aust. Meteor. Mag., 37, 75-81.
Mei, R., and G. Wang, 2011: Impact of sea surface temperature and soil moisture on summer precipitation in the United States based on observational data. J. Hydrometeor., 12, 1086-1099, https://doi.org/10.1175/2011JHM1312.1.

Meyers, M. P., R. L. Walko, J. Y. Harrington, and W. R. Cotton, 1997: New RAMS cloud microphysics parameterization. Part II: The two-moment scheme. Atmos. Res., 45, 3-39, https://doi.org/10.1016/S0169-8095(97)00018-5.

Molinié, G., D. Ceresetti, S. Anquetin, J. D. Creutin, and B. Boudevillain, 2012: Rainfall regime of a mountainous Mediterranean region: Statistical analysis at short time steps. J. Appl. Meteor. Climatol., 51, 429-448, https://doi.org/10.1175/ 2011JAMC2691.1.

Panegrossi, G., R. Ferretti, L. Pulvirenti, and N. Pierdicca, 2011: Impact of ASAR soil moisture data on the MM5 precipitation forecast for the Tanaro flood event of April 2009. Nat. Hazards Earth Syst. Sci., 11, 3135, https://doi.org/10.5194/ nhess-11-3135-2011.

Pielke, R. A., G. Kallos, and M. Segal, 1989: Horizontal resolution needs for adequate lower tropospheric profiling involved with atmospheric systems forced by horizontal gradients in surface heating. J. Atmos. Oceanic Technol., 6, 741-758, https://doi.org/ 10.1175/1520-0426(1989)006<0741:HRNFAL > 2.0.CO;2.

—_, and Coauthors, 1992: A comprehensive meteorological modeling system-RAMS. Meteor. Atmos. Phys., 49, 69-91, https://doi.org/10.1007/BF01025401.

Roberts, N. M., and H. W. Lean, 2008: Scale-selective verification of rainfall accumulations from high-resolution forecasts of convective events. Mon. Wea. Rev., 136, 78-97, https://doi.org/ 10.1175/2007MWR2123.1.

Rodell, M., and Coauthors, 2004: The Global Land Data Assimilation System. Bull. Amer. Meteor. Soc., 85, 381-394, https:// doi.org/10.1175/BAMS-85-3-381.

Ronda, R. J., B. J. van den Hurk, and A. A. Holtslag, 2002: Spatial heterogeneity of the soil moisture content and its impact on surface flux densities and near-surface meteorology. J. Hydrometeor., 3, 556-570, https://doi.org/10.1175/1525-7541(2002)003<0556: SHOTSM $>2.0 . \mathrm{CO} ; 2$.

Rui, H., and H. Beaudoing, 2017: Readme document for global land data assimilation system version 2 (GLDAS-2) products. GES DISC Tech. Doc., 22 pp., https://hydro1.gesdisc.eosdis. nasa.gov/data/GLDAS/README_GLDAS2.pdf.

Schär, C., D. Lüthi, U. Beyerle, and E. Heise, 1999: The soilprecipitation feedback: A process study with a regional climate model. J. Climate, 12, 722-741, https://doi.org/10.1175/ 1520-0442(1999)012<0722:TSPFAP $>2.0$.CO;2.

Schellekens, J., and Coauthors, 2017: A global water resources ensemble of hydrological models: The eartH2Observe Tier-1 dataset. Earth Syst. Sci. Data, 9, 389, https://doi.org/10.5194/ essd-9-389-2017.

Schlemmer, L., C. Hohenegger, J. Schmidli, and C. Schär, 2012: Diurnal equilibrium convection and land surface-atmosphere interactions in an idealized cloud-resolving model. Quart. J. Roy. Meteor. Soc., 138, 1526-1539, https://doi.org/10.1002/qj.1892.

Schwartz, C. S., and Coauthors, 2009: Next-day convectionallowing WRF model guidance: A second look at 2-km versus 4-km grid spacing. Mon. Wea. Rev., 137, 3351-3372, https:// doi.org/10.1175/2009MWR2924.1.

Segal, M., J. R. Garratt, R. A. Pielke, W. E. Schreiber, A. Rodi, G. Kallos, and J. Weaver, 1989: The impact of crop areas in northeast Colorado on midsummer mesoscale thermal circulations. Mon. Wea. Rev., 117, 809-825, https://doi.org/10.1175/ 1520-0493(1989)117<0809:TIOCAI>2.0.CO;2. 
Solomos, S., G. Kallos, J. Kushta, M. Astitha, C. Tremback, A. Nenes, and Z. Levin, 2011: An integrated modeling study on the effects of mineral dust and sea salt particles on clouds and precipitation. Atmos. Chem. Phys., 11, 873-892, https:// doi.org/10.5194/acp-11-873-2011.

Taylor, K. E., 2001: Summarizing multiple aspects of model performance in a single diagram. J. Geophys. Res., 106, 71837192, https://doi.org/10.1029/2000JD900719.

Trier, S. B., F. Chen, and K. W. Manning, 2004: A study of convection initiation in a mesoscale model using high-resolution land surface initial conditions. Mon. Wea. Rev., 132, 29542976, https://doi.org/10.1175/MWR2839.1.

Tuttle, S., and G. Salvucci, 2016: Empirical evidence of contrasting soil moisture-precipitation feedbacks across the United States. Science, 352, 825-828, https://doi.org/10.1126/science.aaa7185.

USGS, 2018a: Digital elevation - Global 30 Arc-Second Elevation (GTOPO30). USGS EROS, accessed 19 December 2018, https://www.usgs.gov/centers/eros/science/usgs-eros-archivedigital-elevation-global-30-arc-second-elevation-gtopo30?qtscience_center_objects $=0 \# q$ t-science_center_objects.

, 2018b: Land cover products - Global Land Cover Characterization (GLCC). USGS EROS, accessed 19 December 2018, https:// www.usgs.gov/centers/eros/science/usgs-eros-archive-land-coverproducts-global-land-cover-characterization-glcc?qt-science center_objects $=0 \#$ qt-science_center_objects.
Van Weverberg, K., N. P. van Lipzig, L. Delobbe, and D. Lauwaet, 2010: Sensitivity of quantitative precipitation forecast to soil moisture initialization and microphysics parametrization. Quart. J. Roy. Meteor. Soc., 136, 978-996, https://doi.org/10.1002/qj.611.

Wagner, W., W. Dorigo, R. de Jeu, D. Fernandez, J. Benveniste, E. Haas, and M. Ertl, 2012: Fusion of active and passive microwave observations to create an essential climate variable data record on soil moisture. ISPRS Ann. Photogramm. Remote Sens. Spat. Inf. Sci., 7, 315-321.

Walko, R. L., and C. J. Tremback, 2005: Modifications for the transition from LEAF-2 to LEAF-3. ATMET Tech. Note, 13 pp., http://www.atmet.com/html/docs/rams/RT1-leaf2-3.pdf.

Wang, Y., J. Yang, Y. Chen, P. De Maeyer, Z. Li, and W. Duan, 2018: Detecting the causal effect of soil moisture on precipitation using convergent cross mapping. Sci. Rep., 8, 12171, https:// doi.org/10.1038/s41598-018-30669-2.

Webb, R. W., C. E. Rosenzweig, and E. R. Levine, 2000: Global soil texture and derived water-holding capacities. ORNL DAAC, accessed 19 December 2018, https://doi.org/10.3334/ ORNLDAAC/548.

Weedon, G. P., G. Balsamo, N. Bellouin, S. Gomes, M. J. Best, and P. Viterbo, 2014: The WFDEI meteorological forcing data set: WATCH Forcing Data methodology applied to ERA-Interim reanalysis data. Water Resour. Res., 50, 7505-7514, https:/doi.org/ 10.1002/2014WR015638. 